\title{
Receptor-interacting serine/threonine-protein kinase 1 promotes the progress and lymph metastasis of gallbladder cancer
}

\author{
GUANGWEI ZHU ${ }^{1-3}$, QIANG DU ${ }^{1,2}$, XIAO CHEN $^{1,2}$, XIAOQIAN WANG ${ }^{1}$, \\ NANHONG TANG ${ }^{1}$, FEIFEI SHE $^{2}$ and YANLING CHEN ${ }^{1,2}$
}

\author{
${ }^{1}$ Department of Hepatobiliary Surgery and Fujian Institute of Hepatobiliary Surgery, Union Hospital, \\ Fujian Medical University; ${ }^{2}$ Key Laboratory of Ministry of Education for Gastrointestinal Cancer and \\ Key Laboratory of Tumor Microbiology, School of Basic Medical Sciences, Fujian Medical University, \\ Fuzhou, Fujian 350001; ${ }^{3}$ Department of Gastrointestinal Surgery 2 Section, The First Hospital \\ Affiliated to Fujian Medical University, Fuzhou, Fujian 350005, P.R. China
}

Received October 28, 2018; Accepted May 30, 2019

DOI: 10.3892/or.2019.7331

\begin{abstract}
Receptor-interacting serine/threonine-protein kinase 1 (RIP-1) is highly expressed in gallbladder cancer, and is very important in promoting tumor proliferation and invasion. The underlying mechanism in this promotion is the RIP-1-nuclear factor $\kappa-\mathrm{B}(\mathrm{NF}-\mathrm{\kappa B})$ and activator protein 1 (AP-1)-vascular endothelial growth factor-C (VEGF-C) signaling pathways. However, the precise mechanisms by which RIP-1 regulates VEGF-C expression are still unknown. The current study aims to clarify the detailed mechanisms by which RIP-1 upregulates VEGF-C expression. In the current study, the authors constructed various VEGF-C promoter deletions, VEGF-C promoter mutations and RIP-1 overexpression plasmids, and silenced RIP-1 with a small interfering RNA. Promoter analysis, an electrophoretic mobility shift assay, a chromatin immunoprecipitation assay was then performed, and an orthotopic transplantation model in nude mice was established by modified methods previously used. The authors also found that the core region for luciferase activity in the VEGF-C promoter was -332 to $-190 \mathrm{nt}$, in which there are two overlapping AP-1 sites and an NF- $\kappa$ B site. RIP-1 was demonstrated to activate transcription factors NF- $\kappa \mathrm{B}$ and
\end{abstract}

Correspondence to: Professor Yanling Chen, Department of Hepatobiliary Surgery and Fujian Institute of Hepatobiliary Surgery, Union Hospital, Fujian Medical University, 29 Xin-Quan Road, Fuzhou, Fujian 350001, P.R. China

E-mail: drchenyl@126.com

Professor Feifei She, Key Laboratory of Ministry of Education for Gastrointestinal Cancer and Key Laboratory of Tumor Microbiology, School of Basic Medical Sciences, Fujian Medical University, 1 Xue-Yuan Road, Fuzhou, Fujian 350001, P.R. China

E-mail: shefeifei@yeah.net

Key words: gallbladder cancer, receptor interacting protein-1, lymph metastasis, vascular endothelial growth factor-C, signal pathway
AP-1 to combine with the core region and enhance VEGF-C promoter activity. In conclusion, the current study illustrated the mechanisms by which RIP-1 regulates VEGF-C expression, by activating NF- $\mathrm{BB}$ and AP-1 to combine with the -332 to $-190 \mathrm{nt}$ area of the VEGF-C promoter. By establishing an orthotopic mouse model of gallbladder cancer tumors, it was further elucidated that RIP-1 promotes gallbladder cancer metastasis. The findings provide evidence that targeting RIP-1 may prove to be useful in the treatment of gallbladder cancer.

\section{Introduction}

Gallbladder cancer is a very rare disease with an incidence of 1.13/100,000 and a 5-year survival rate for all stages at approximately 5\%; it has highly variable characteristics and presentations (1-3). Some research articles have reported that gallbladder cancer is diagnosed late and that treatment is ineffective. Resection is still the most effective and most likely curative treatment for gallbladder cancer (4). However, numerous patients present late in the course of the disease, when surgical intervention is no longer beneficial (5). Therefore, the prognosis of patients with gallbladder cancer remains poor $(1,2)$. It is necessary to study the molecular mechanisms that effect the progression of gallbladder cancer, as these may be potential therapeutic targets for gallbladder cancer treatment.

To the best of our knowledge, receptor-interacting serine/threonine-protein kinase 1 (RIP-1) is overexpressed in gallbladder cancer tissues, while it has low expression in normal tissues (6). A previous study by our groups showed that increased RIP-1 expression is common in gallbladder cancer tissues (6). It was also found that RIP-1 expression was markedly correlated with the clinical stage in patients with gallbladder cancer (6). There was evidence that a reduction of RIP-1 expression in gallbladder cancer cells can exert inhibitory effects on the ability of cancer cells to grow and invade in vitro and in vivo (6). Furthermore, the underlying mechanisms of RIP-1 affecting gallbladder cancer cell biological behaviors were studied, and it was found that RIP-1-nuclear factor $\kappa-B$ $(\mathrm{NF}-\kappa \mathrm{B})$ and activator protein 1 (AP-1)-vascular endothelial 
growth factor-C (VEGF-C) signaling pathways play an important role in RIP-1 promoting gallbladder cancer cell growth and invasion (6). These are consistent with a previous study, which demonstrated that RIP-1 is an independent prognostic factor in glioblastomas (7).

Previous studies have found that RIP-1 plays a vital role during cellular stress caused by different factors, such as inflammation and DNA damage (8-12). These responses activated RIP-1, with signals being transmitted when activated RIP-1 activated the transcription factors NF- $\kappa \mathrm{B}$ and AP-1 (8-12). These further triggered the expression of downstream genes, and promoted cell survival and differentiation (8-12). The activation of NF- $\mathrm{kB}$ in human cancer is very common (13), and in a previous study by our group, it was demonstrated that NF- $\mathrm{\kappa B}$ activation plays a vital role in gallbladder cancer progression (14). Although a previous study by our group revealed that RIP-1 could upregulate VEGF-C expression though the RIP-1-NF- $\kappa$ B and AP-1 signaling pathways (6), the precise mediation mechanisms of this upregulation are still unknown.

In our previous study, the authors found that knockdown of RIP-1 expression suppressed the growth of subcutaneous xenograft tumors of gallbladder cancer cells (6). In the animal model of gallbladder cancer established by our group, liver, lung and lymph node metastasis, and ascites had not developed (6). These findings were consistent with a study by Horiuchi et al (15), who suspected that the subcutaneous xenograft gallbladder cancer model cannot provide a suitable microenvironment for tumor cells. The findings of our previous study therefore support the view that orthotopic xenograft models of gallbladder cancer are better than the subcutaneous xenograft gallbladder cancer model for studying the biological characteristics of gallbladder cancer (16).

In the present study, the authors investigated the specific mechanisms by which RIP-1 regulates the expression of VEGF-C. This was performed to support the hypothesis that RIP-1 promotes growth and lymph node metastasis in gallbladder cancer. Furthermore, the authors of the current study modified the orthotopic xenograft model of gallbladder cancer to further study RIP-1 and its influence on the biological behavior of gallbladder cancer.

\section{Materials and methods}

Cell culture. The gallbladder cancer cell line GBC-SD and NOZ were purchased from Shanghai Institutes for Biological Science (Shanghai, China). SGC-996 was provided by the Tumor Cytology Research Unit, Medical College, Tongji University (Shanghai, China). NOZ cells were obtained from a 48-year-old female patient with gallbladder cancer, which was established by Health Science Research Resources Bank in Japan (17). All three cell lines were cultured in Dulbecco's Modified Eagle's Medium (DMEM) supplemented with 10\% fetal bovine serum (FBS; both Life Technologies; Thermo Fisher Scientific, Inc.). The three gallbladder cancer cell lines were incubated at $37^{\circ} \mathrm{C}$ under $95 \%$ air and $5 \% \mathrm{CO}_{2}$.

Plasmid constructs. Genomic DNA was extracted from NOZ cells using the DNeasy Blood \& Tissue kit (Qiagen, Inc.), which was used as a template for polymerase chain reaction (PCR) amplification. The plasmid pGL3B-2000 was constructed by ligation of the longest PCR-produced VEGF-C promoter (nucleotides $-2,000$ to +1 , relative to the transcription start site). The longest fragment contained the HindIII and XhoI restriction site, which was connected to the pGL3-Basic vector (Promega Corporation). Different kinds of VEGF-C promoter plasmids were constructed, including pGL3B-1500, pGL3B-1000, pGL3B-487, pGL3B-332, pGL3B-190 and pGL3B-332NF- $\mathrm{BBmut}$. A total of $1 \mu \mathrm{g}$ plasmids in each lane were resolved by electrophoresis using $2 \%$ ethidium bromide-stained agarose gels. Bands were visualized by densitometric scanning gels. Analyses were performed using Quantity One software (version 4.6; Bio-Rad Laboratories, Inc.). The plasmids were stored by the Fujian Institute of Hepatobiliary, Union Hospital, Fujian Medical University (Fuzhou, China). The primers for PCR amplification are as follows: Forward, 5'-TGACTCGAGCTGCCCCTGCGCCCG CCGCC-3', reverse, 5'-TGAAAGCTTCCTCCCCTTCCC CGAAGT-3' (Xhol and HindIII restriction sites are shown in italics). pGL3B-332 was used as a template for the construction of AP-1-binding site mutants. The authors constructed the mutant plasmids using overlap PCR technology (18). The mutant plasmids were named pGL3B-332AP-1 mut, and the NF- $\kappa \mathrm{B}$ and AP-1 co-mutant plasmids were constructed and named pGL3B-332 mut. To obtain the overexpression plasmids, pcDNA3.1-NF- $\mathrm{kB}(\mathrm{p} 65)$ and pcDNA3.1-AP-1, PCR was carried out with a superscript library (Life Technologies; Thermo Fisher Scientific, Inc.) using the template human full-length cDNA sequence of NF- $\kappa \mathrm{B}(\mathrm{p} 65) / \mathrm{AP}-1$. The PCR-generated NF- $\mathrm{BB}(\mathrm{p} 65) / \mathrm{AP}-1$ gene was inserted into the XhoI-HindIII sites of pcDNA3.1 (Promega Corporation). All of the above constructs were confirmed by DNA sequencing, which was performed by Bosune Biological Company. The primers for PCR amplification are shown in Table I.

Western blot analysis. These experiments and results analysis were carried out as described previously $(6,14)$. Cells were lysed with Western IP cell lysis buffer (Beyotime Institute of Biotechnology) containing PMSF (Amresco, LLC) on ice for $30 \mathrm{~min}$. Cell protein ( $30 \mu \mathrm{g} / \mathrm{lane})$ was separated by SDS-PAGE on a $10 \%$ gel and transferred onto a $0.45 \mu \mathrm{M}$ PVDF membrane (GE Healthcare). The membrane was blocked with $0.5 \%$ bovine serum album (Amresco, LLC) at room temperature for $2 \mathrm{~h}$. The following monoclonal primary antibodies were used in the western blot analysis: Mouse anti-human RIP-1 antibody (cat. no. ab72139; 1:1,000; Abcam), rabbit anti-human AP-1 (cat. no. ab32137; 1:1,000; Abcam), mouse anti-human NF-кB (p65; cat. no. 8242; 1:500; Cell Signaling) and mouse anti-human $\beta$-actin (cat. no. sc-47778; 1:1,500; Santa Cruz Biotechnology, Inc.) overnight at $4^{\circ} \mathrm{C}$. The membranes were washed three times with TBST $(0.1 \%$ Tween-20) for 10 min each at room temperature. The membranes were incubated with anti-rabbit immunoglobulin (Ig)G (cat. no. sc-2357) and mouse IgGк (cat. no. sc-516102; both dilution 1:4,000; Santa Cruz Biotechnology, Inc.) horseradish peroxidase-conjugated secondary antibodies at room temperature for $1 \mathrm{~h}$. Visualization of the immunoreactive proteins was performed by chemiluminescence kit (BeyoECL Plus; Beyotime Institute of Biotechnology). The intensities of band signals were quantified using Quantity One densitometric software (version 4.6.3); the relative intensity of the target bands was normalized to that of $\beta$-actin. 
Table I. List of oligonucleotides used in the current study.

Oligonucleotides names

Sequences $\left(5^{\prime}-3^{\prime}\right)$

A, pGL3B-332 mutation

Mut AP-1 F

Mut AP-1 R

Mut NF- $\kappa \mathrm{B} F$

Mut NF- $\kappa \mathrm{B}$ R

P1 co-primer F

P1 co-primer R
CGCAGGCAGAGGGCGCGTTTTTCATGCCCTGCCCCTGCG

CGCAGGGGCAGGGCATGAAAAACGCGCCCTCTGCCTGCG

AGGCGAGGGAAACGAAGAGCTCCAGGGAGA

TCTCCCTGGAGCTCTTCGTTTCCCTCGCCT

TACGGGAGGTACTTGGAGCGG

TTCCAGGAACCAGGGCGTATC

B, pcDNA3.1-expression plasmids

\begin{tabular}{|c|c|}
\hline AP-1 F & GCCTCGAGGCCACCATGACTGCAAAGATGGAAACG \\
\hline AP-1 R & GCAAGCTTTCAAAATGTTTGCAACTGCTGCGTT \\
\hline $\mathrm{NF}-\kappa \mathrm{B} F$ & GCCTCGAGGCCACCATGGACGAACTGTTCCCCCT \\
\hline $\mathrm{NF}-\kappa \mathrm{B} \mathrm{R}$ & GCAAGCTTTTAGGAGCTGATCTGACTCA \\
\hline RIP-1 F & GCCTCGAGGCCACCATGCAACCAGACATGTCCTTG \\
\hline RIP-1 R & GCAAGCTTGGGTTAGTTCTGGCTGACGTAAATC \\
\hline
\end{tabular}

C, Electrophoretic mobility shift assay

Biotin-labeled probe

$\mathrm{NF}-\kappa \mathrm{B}$ cold probe

$\mathrm{NF}-\kappa \mathrm{B}$ mutation probe

Biotin-labeled probe

AP-1 cold probe

AP-1 mutation probe
Biotin-GAGGGAAACGGGGAGCTCCAGGGAG

AGTTGAGGGGACTTTCCCAGGC

AGTTGAGGAAACTTGCCCAGGC

Biotin-AGAGGGCGCGTCAGTCATGCC

AGAGGGCGCGTCAGTCATGCC

AGAGGGCGCGTTTTTCATGCC

$\mathrm{D}$, Chromatin immunoprecipitation assay

AP-1 F

AP-1 R

$N F-\kappa B$ F

$\mathrm{NF}-\kappa \mathrm{B} R$

\section{CGAGGGAGAGTGAGAGGGGAGGGCA \\ GCGGCGGGCGCAGGGGCAGGGCATG \\ GACAGGGGCGGGGAGGGAGA \\ CTCACTCTCCCTCGGAAGCCGTCTC}

Mutant bases are underlined; restriction sites are shown in italics. F, forward; R, reverse; RIP-1, receptor-interacting serine/threonine-protein kinase $1 ; \mathrm{NF}-\kappa \mathrm{B}$, nuclear factor $\kappa-\mathrm{B} ; \mathrm{AP}-1$, activator protein 1 ; mut, mutant.

Transfection and dual-luciferase reporter assay. NOZ cells were seeded at a density of $2 \times 10^{5}$ cells per well in 12-well plates. DNA transfection was performed in by use of Lipofectamine 2000 (Life Technologies; Thermo Fisher Scientific, Inc.), in accordance with the manufacturer's protocol. The small interfering (si)RNAs for NF- $\kappa$ B and AP-1 were 5'-CUCAAGAUCUGCCGAGUGA-3' and 5'-CCT CAGCAACTTCAACCC-3', respectively, and were synthesized by Beyotime Institute of Biotechnology; 100 pmol of each siRNA were transfected into the cells. At $48 \mathrm{~h}$ after transfection, the mRNA and proteins were extracted. NOZ cells were also co-transfected with the siRNAs and different VEGF-C promoter vectors, and cells were lysed $48 \mathrm{~h}$ after transfection. A total of $20 \mu \mathrm{g}$ of cell lysate was used for the detection of intracellular luciferase activity, following the manufacturer's protocol of Dual-Luciferase ${ }^{\circledR}$ Reporter
(DLR ${ }^{\mathrm{TM}}$ ) Assay system (Promega Corporation). The Renilla luciferase expression vector pRL-TK (Promega Corporation) was used for normalization and the promoter-less vector pGL3-Basic served as the negative control. Luminescence measurement was performed on a luminometer (Orion II Microplate Luminometer; Berthold Detection Systems $\mathrm{GmbH})$. Each transfection was performed in duplicate and data were expressed as the mean \pm standard deviation of three separate experiments.

Identification of putative transcription factor binding sites. A computer-based search for potential transcription factor binding site motifs was carried out on TESS (http://www.cbil.upenn.edu/cgi-bin/tess/tess) (19), TFBIND (http://tfbind.hgc.jp/) (20) and TFSEARCH (http://ww w.cbrc. jp/research/db/TFSEARCH.html) (21). 
Nuclear extraction and electrophoretic mobility shift assay (EMSA). Transfected cells $\left(10^{7}\right)$ were transfected and the Nuclear Extraction kit (Beyotime Institute of Biotechnology) was used to extract nuclear proteins. The 5'-biotin end-labeled oligonucleotides were synthesized by Beyotime Institute of Biotechnology and used as probes. Unlabeled oligonucleotide cold probes or mutated cold probes with NF- $\kappa \mathrm{B}$ and AP-1 mutation sites were used as competitors. The oligonucleotide sequences are shown in Table I. Nuclear protein was subjected to hybridization to these oligonucleotide probes. Nuclear proteins, including the interaction of NF- $\kappa$ B/AP-1 with the dsDNA probe, were tested by use of the Chemiluminescent Nucleic Acid Detection Module kit (cat no. 89880; Thermo Fisher Scientific, Inc.), in accordance with the manufacturer's protocol.

Briefly, the binding buffer mixture was prepared of $1 \mathrm{X}$ binding buffer supplemented with $5 \%$ glycerol, $200 \mathrm{mM} \mathrm{KCl}$ and $100 \mathrm{mM} \mathrm{MgCl}_{2}$ (cat. no. 20148X; Thermo Fisher Scientific, Inc.). A total of $7 \mu \mathrm{g}$ of extracted nuclear proteins were incubated with $1 \mu \mathrm{g}$ of poly(deoxyinosinic-deoxycytidylic) and 0.02 pmol labeled probe in a final volume of $10 \mu \mathrm{l}$ for $20 \mathrm{~min}$ at room temperature. The competition assay was performed using $0.5 \mathrm{pmol}$ biotin probes and $50 \mathrm{pmol}$ cold/mut probes, as well as 50-100 or 50-200 fold molar excess of cold probes or cold mutated probes, which added to other component for 5 min before adding biotin-labeled probes. Then, proteins were subjected to electrophoresis on a $6 \%$ non-denaturing pre-made polyacrylamide gel (Invitrogen; Thermo Fisher Scientific, Inc.). The complexes were transferred to a nylon membrane (GE Healthcare) and fixed for 3 min using a UV crosslinker (UVP, LLC). The biotin end-labeled DNA was detected by the addition of a streptavidin-horseradish peroxidase conjugate and a chemiluminescent substrate from the Chemiluminescent Nucleic Acid Detection Module kit intensities of band signals were quantified using Quantity One densitometric software (version 4.6.3). The experimental results are shown in bars.

Chromatin immunoprecipitation (ChIP)-PCR. Transfected NOZ cells $\left(10^{7}\right)$ were cultured and cross-linked using formaldehyde (final concentration, 1\%) at room temperature for $10 \mathrm{~min}$. Following this, $125 \mathrm{mM}$ glycine was added for $5 \mathrm{~min}$ to stop cross-linking from occurring at room temperature. Cells were rinsed twice with ice-cold PBS and then collected by centrifuging at 3,500 x g for $5 \mathrm{~min}$ at $4^{\circ} \mathrm{C}$. The cells were resuspended in $0.75 \mathrm{ml} \mathrm{FA}$ lysis buffer (Abcam) and placed on ice for $15 \mathrm{~min}$. Cell lysates were sonicated for $20 \mathrm{~min}$. Immunoprecipitation was conducted with anti-NF- $\kappa \mathrm{B}$ and anti-AP-1 antibodies (both 1:200) overnight at $4^{\circ} \mathrm{C}$ followed by $80 \mu \mathrm{l}$ of pre-blocked protein $\mathrm{A} / \mathrm{G}$ beads overnight at $4^{\circ} \mathrm{C}$. DNA was then recovered by phenol/chloroform extraction and ethanol precipitation in the presence of glycogen [glycogen: $10 \mu \mathrm{l}(5 \mathrm{mg} / \mathrm{ml})$; ethanol: $25 \mu \mathrm{l}$ ), and dissolved in $100 \mu \mathrm{l}$ sterile distilled water. The target DNA fractions were amplified by PCR [LA Taq ${ }^{\circledR}$ DNA polymerase (Takara Bio, Inc.) 28 cycle of denaturation at $95^{\circ} \mathrm{C}$ for $30 \mathrm{sec}$, annealing at $56^{\circ} \mathrm{C}$ for $30 \mathrm{sec}$, and extension at $72^{\circ} \mathrm{C}$ for $30 \mathrm{sec}$ followed by $10 \mathrm{~min}$ for final extension at $72^{\circ} \mathrm{C}$ ], and the primers used are as follows: NF- $\kappa \mathrm{B}$ site in VEGF-C promoter forward, 5'-GACAGGGGCGGGGAGGGA GA-3', and reverse, 5'-CTCACTCTCCCTCGGAAGCCGTCT C-3'; and AP-1 site in VEGF-C promoter forward, 5'-CGAGGG AGAGTGAGAGGGGAGGGCA-3', and reverse, 5'-GCGGCG GGCGCAGGGGCAGGGCATG-3'.
Establishment of the orthotopic xenograft model by modified methods. A total of 15 male 4-6 week-old athymic $\mathrm{BALB} / \mathrm{c} \mathrm{nu} / \mathrm{nu}$ mice weighing 15-20 g were purchased from the Shanghai SLAC Laboratory Animals Company, and were raised in the Experimental Center of Fujian Medical University in a climate-controlled room at a temperature of $20-26^{\circ} \mathrm{C}$ (termed barrier system), with a relative humidity of $40-70 \%$ and light/dark cycle of $12 / 12 \mathrm{~h}$ and free access to food and water. The mice were treated according to the institutional guidelines, and the study was approved by the Ethics Committee of the Medical Faculty of the Fujian Medical University.

To build the orthotopic xenograft model of gallbladder cancer in nude mice, untreated NOZ cells [NOZ-control (con) group], NOZ cells were treated with a negative control (NC) siRNA (NOZ-NC group), and NOZ cells were treated with a siRNA against RIP-1 (NOZ-RIPsi group) cells were used (6). The NC sequence was 5'-TTCTCCGAACGTGTCACGT-3' and the RIPsi sequence was 5'-GCACAAATACGAACTTCA A-3'. These sequences were obtained from Genechem Co., Ltd. These were stored by the Fujian Institute of Hepatobiliary, Union Hospital, Fujian Medical University. A total of $2 \mu \mathrm{g}$ of each siRNA were transfected into NOZ cells in DMEM with $10 \%$ FBS at $\sim 90 \%$ confluency at $37^{\circ} \mathrm{C}$ under $95 \%$ air and $5 \%$ $\mathrm{CO}_{2}$ for $72 \mathrm{~h}$. The culture medium was replaced with DMEM containing $2 \mu \mathrm{g} / \mathrm{ml}$ puromycin (Sigma-Aldrich; Merck KGaA). When the stably transfected cells we obtained, the cells were continuously maintained in $1 \mu \mathrm{g} / \mathrm{ml}$ of puromycin for later experiments, and termed the NOZ-NC group and the NOZ-RIPsi group.

To establish the mouse model, differently treated NOZ cells were harvested at a concentration of $10^{7}$ cells $/ \mathrm{ml}$. These cells were placed on ice for the following experiments. The nude mice were anesthetized a mixed anesthetic (ketamine $80 \mathrm{mg} / \mathrm{kg}$, xylazine $8 \mathrm{mg} / \mathrm{kg}$ ). The mice did not consume water or food for $4 \mathrm{~h}$ before anesthesia. After anesthesia, conventional complexing iodine was used to disinfect the skin of the mice. An abdominal midline incision was made (approximately $1.0 \mathrm{~cm}$ ), after which the gallbladder of the nude mice was exposed. The gallbladder was located in the middle of liver lobes. A total of $20 \mu \mathrm{l}$ of suspended cells was mixed with $20 \mu 1$ Matrigel.

The $40 \mu 1$ mixture was then taken up by a modified insulin syringe. The operation was performed on ice to keep the Matrigel in a liquid state. The syringe was then used to puncture through the gallbladder, the syringe was then withdrawn from the puncture site into the gallbladder, leaving a hole on one side. The gallbladder bile them leaked onto a swab. With the needle still inside, $40 \mu \mathrm{l}$ of the cell mixture was slowly injected into the empty gallbladder. After $30 \mathrm{sec}$, when the cells suspension solidified, the syringe was withdrawn from the gallbladder. The gallbladder and liver were placed in the abdominal cavity, and then the abdominal wall was sutured. There were five mice in each experimental group. After regaining consciousness, the mice were raised in a sterile environment. The physical condition of the mice was monitored for 4 days after surgery, and then recorded once every 2 days for several weeks. A total of 5 weeks later, the mice were euthanized by means of cervical dislocation and the mice were dissected in a sterile environment. Tumor samples were 
fixed in $10 \%$ formaldehyde solution at room temperature for $24 \mathrm{~h}$ and some samples were kept in liquid nitrogen.

Hematoxylin and eosin staining, immunohistochemistry, and evaluation. The primary tumors and lymph node were fixed in $10 \%$ neutral buffer formalin for $24 \mathrm{~h}$ at room temperature. These tissues were then trimed and embedded in paraffin. Samples were cut in $4-\mu \mathrm{m}$-thick serial sections, and stained with hematoxylin for $3 \mathrm{~min}$ and eosin for $10 \mathrm{sec}$ both at room temperature. The samples were then observed under an optical microscope (DM4000B; Leica) at a magnification of $x 400$.

Immunohistochemistry and its evaluation were carried out as previously described (6). Briefly, the sections were blocked in $10 \%$ normal goat serum (Vector Laboratories, Inc.) at room temperature for $15 \mathrm{~min}$ and then the sections were incubated in $3 \% \mathrm{H}_{2} \mathrm{O}_{2}$ at room temperature for $35 \mathrm{~min}$ to inactivate endogenous peroxidase. Thereafter, primary antibodies were incubated with $4-\mu \mathrm{m}$-thick slices overnight in humidified boxed at $4^{\circ} \mathrm{C}$, followed by incubation with $60 \mu \mathrm{l}$ ready-to-use biotin-conjugated secondary antibodies from the UltraSensitive S-P kit (cat. no. 9710; Fuzhou Maixin Biotech, Co., Ltd.) at room temperature for $1 \mathrm{~h}$. Then sections were then washed in TBST three times (5 min each) and incubated with streptavidin-peroxidase from the UltraSensitive S-P kit in dark at room temperature for $10 \mathrm{~min}$. DAB (ZSJQB Co., Ltd.) for 4-6 min at room temperature and hematoxylin for $3 \mathrm{~min}$ at room temperature. The samples were then observed with a DM4000B microscope at a magnification of $x 400$. The following primary antibodies were used: Mouse monoclonal anti-human RIP-1 (1:500), rabbit polyclonal anti-human VEGF-C (1:150; cat. no. ab9546; Abcam) and rabbit polyclonal anti-mouse lymphatic vessel endothelial hyaluronic acid receptor 1 (LYVE-1; cat. no. AF2125; 1:250; R\&D Systems, Inc.). The expression of RIP-1 and VEGF-C were evaluated using the Image-Pro Plus 6.0 software (Media Cybernetics, Inc.). Three slices were randomly selected for each group and five fields were selected for each slice. The expression of RIP-1 and VEGF-C was semi-quantitatively analyzed in fifteen fields using the following formula: Mean optical density = integral optical density / the positive area.

Microlymphatic vessel counting. The $4-\mu \mathrm{m}$-thick slices were observed at low magnification (x100) using a DM4000B microscope to detect areas with the most intense staining and apparent highest occurrence of microvessels, thus named 'the hotspot' (22). Two physiologists independently evaluated the slides for microvessels using a DM4000B microscope at a magnification of $x 400$. Brown vessels without red blood cells in their lumen were considered microlymphatic vessels. Vessels with a single immunoreactive layer of endothelial cells or endothelial cells were counted as a blood vessel (23). The density of positive cells in microlymphatic vessels were counted with a DM4000B microscope at a magnification of $\mathrm{x} 400$.

Statistical analysis. All statistical analyses were performed using GraphPad Prism 5 software (GraphPad Software, Inc.). Data were analyzed by ANOVA with Tukey's post hoc test when more than two groups were compared or Student's t-test when two groups were compared. The data were expressed as the mean \pm standard deviation. A P-value of $<0.05$ was considered to indicate a statistically significant difference.

\section{Results}

Region of -332 nt to +1 is crucial for the functions of the $V E G F-C$ promoter and for the effect of RIP-1 on VEGF-C promoter activity. Gel electrophoresis was used to detect the constructed plasmids, including various promoter deletions of VEGF-C (Fig. 1A). These plasmids were transfected transiently into NOZ cells. As shown in Fig. 1B, the cells revealed similar luciferase activities for pGL3B-1500, pGL3B-1000 and pGL3B-332, while luciferase activities were significantly increased for pGL3B-487 and decreased for pGL3B-190 compared with pGL3B-332. This indicates that the region of -332 to $+1 \mathrm{nt}$ is key to the activities of the VEGF-C promoter. To investigate the luciferase activities of the VEGF-C promoter in gallbladder cancer cell lines, SGC-996, GBC-SD and NOZ cell lines were used to test pGL3B-332 luciferase activity. As shown in Fig. 1C, luciferase activity were significantly higher in NOZ cells and GBC-SD cells compared with that in SGC996 cells. The luciferase activity was highest in NOZ cells, moderate in GBC-SD and lowest in SGC-996. The expression of the RIP-1 protein was assessed by western blot analysis after transfecting different concentrations of pcDNA3.1-RIP-1 plasmids in NOZ cells for $48 \mathrm{~h}$. RIP-1 protein expression in NOZ cells significantly increased in a dose-dependent manner of pcDNA3.1-RIP-1 concentration compared with the untreated cells (Fig. 1D and E). RIP-1 overexpression significantly increased the relative luciferase activity of the pGL3B-332 plasmid compared with the untreated group and this increase was dependent on pcDNA3.1-RIP-1 concentration (Fig. 1F). These results suggested that RIP-1 affects the luciferase activity of the VEGF-C promoter.

Regulation of the VEGF-C promoter by the transcription sites of $N F-\kappa B$ and AP-1. TESS and TFBIND were used to search for putative transcription factor binding sites. Previously, our team found that the $\mathrm{NF}-\kappa \mathrm{B}$ site on the VEGF-C promoter regulates its transcriptional activity (24). That study focused on the regulation of NF- $\kappa$ B by RIP-1. NF- $\kappa$ B and two AP-1 sites (overlapped partially and very similiar in the DNA sequences) were identified in the -332 nt to +1 region of the promoter (Fig. 2A). A mutated NF- $\mathrm{BB}$ site and two mutated AP-1 site in pGL3B-332 were constructed, and the promoter luciferase activity of the mutant plasmids was measured. As revealed in Fig. 2B, both pGL3B-332-NF- $\kappa$ B mut and pGL3B-332-AP-1 mut had significantly lower activity than the non-mutated control plasmid, pGL3B-332. In addition, the co-mutation of the NF- $\kappa$ B site and two AP-1 sites, pGL3B-332 mut, had significantly lower luciferase activity than that of pGL3B-332, pGL3B-332- NF- $\kappa$ B mut and pGL3B-332-AP-1 mut plasmids. This suggests that the NF- $\kappa \mathrm{B}$ site and two AP-1 sites may work together to encourage the luciferase activity of the VEGF-C promoter. Overexpression of RIP-1 significantly increased the relative luciferase activity of the pGL3B-332 plasmid and the luciferase activity also increased with increasing concentrations of pcDNA3.1-RIP-1 (Fig. 2C and D). However, the $\mathrm{NF}-\kappa \mathrm{B}$ mutation site, AP-1 mutation sites, and co-mutation NF- $\kappa \mathrm{B}$ and AP-1 sites markedly impaired the ability of RIP-1 

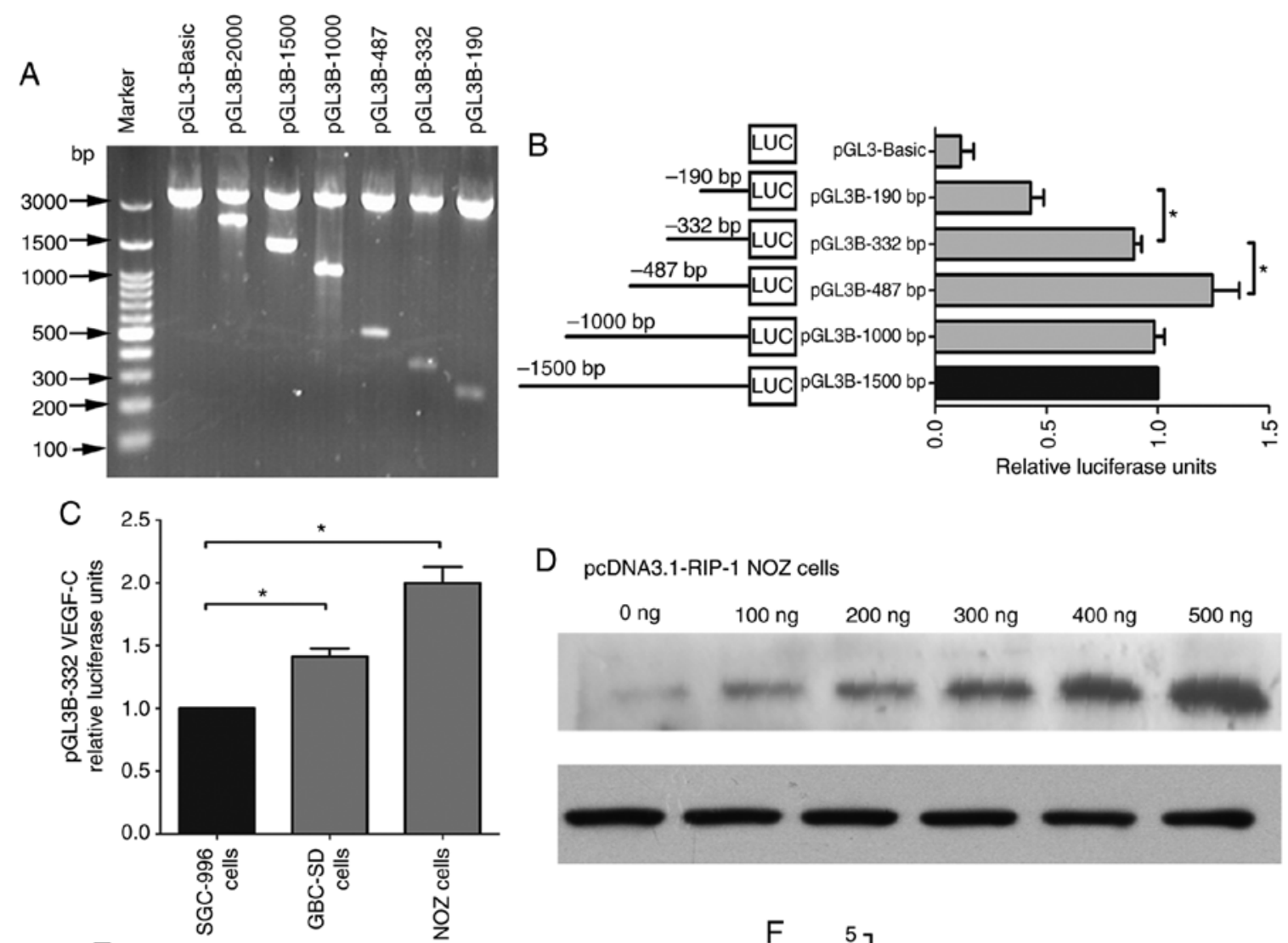

D pcDNA3.1-RIP-1 NOZ cells
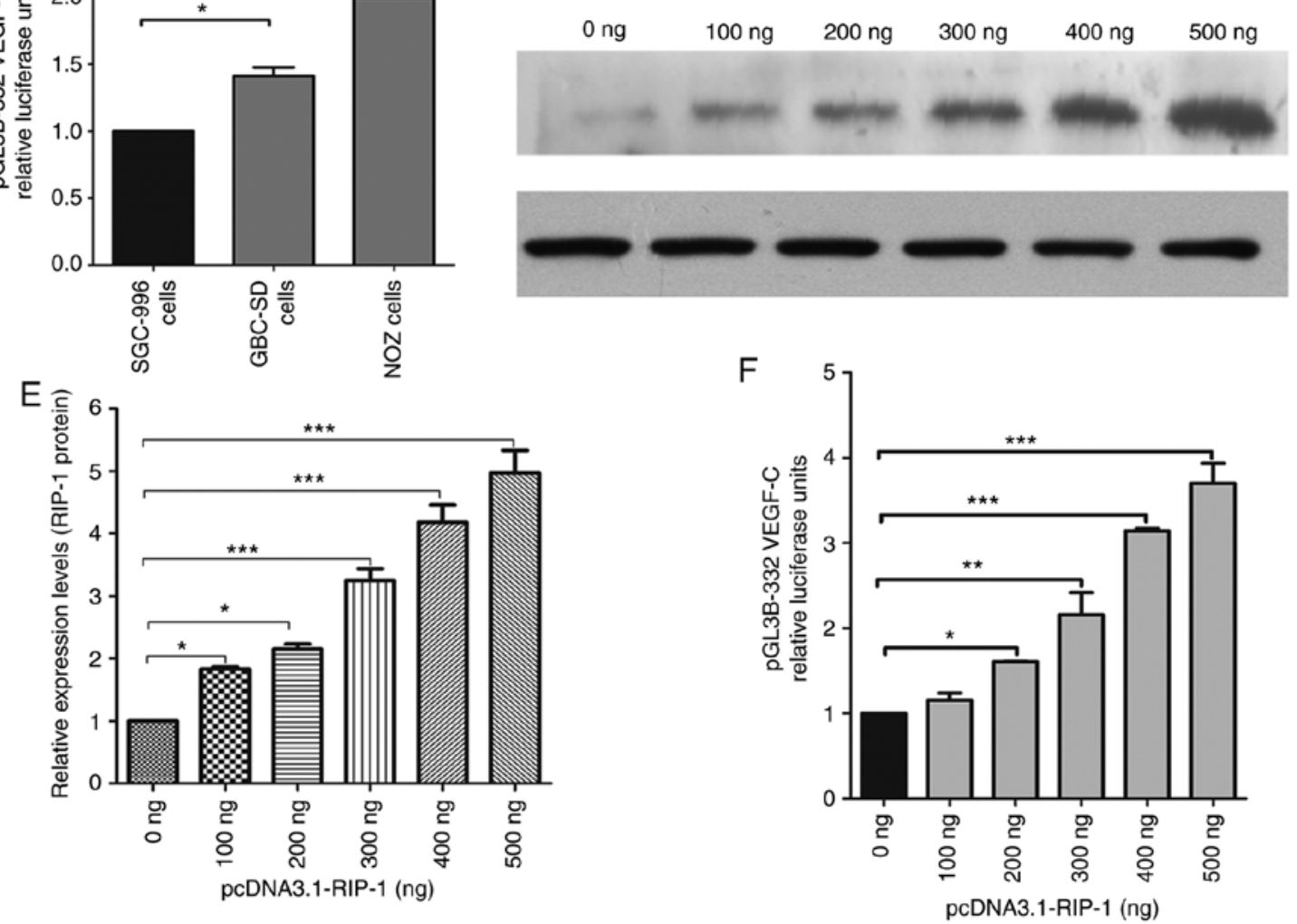

Figure 1. VEGF-C promoter activity analysis and the effects of RIP-1 on VEGF-C promoter activity. (A) Various VEGF-C promoter deletions were assessed by agarose gel electrophoresis. (B) Luciferase activity analysis of VEGF-C promoter following the transfection of NOZ cells with plasmids including different VEGF-C promoter fragments. The Renilla luciferase expression vector pRL-TK was used for normalization and the promoterless vector pGL3-Basic served as the negative control. After transfection for $48 \mathrm{~h}$, relative luciferase activities were measured. ${ }^{2} \mathrm{P}<0.05$ vs. pGL3B-332. (C) VEGF-C promoter activity in different gallbladder cancer cell lines. Different gallbladder cancer cells were co-transfected with pGL3B-332 and pRL-TK plasmids. After $48 \mathrm{~h}$ transfection, relative luciferase activities were measured. RIP-1 (D) protein and (E) mRNA levels were measured after transfection for $48 \mathrm{~h}$ with different concentrations of pcDNA3.1-RIP-1 plasmids in NOZ cells. (F) VEGF-C promoter activities were assessed after the co-transfection of pGL3B-332 and pRL-TK into NOZ cells with different concentration of pcDNA3.1-RIP-1. The relative luciferase units were measured after transfection for $48 \mathrm{~h}$. ${ }^{*} \mathrm{P}<0.05,{ }^{* * *} \mathrm{P}<0.01,{ }^{* * * *} \mathrm{P}<0.001$ as indicated. Each transfection was carried out in duplicate and the data were expression as the mean \pm standard deviation of three experiments. NF- $\kappa \mathrm{B}$, nuclear factor $\kappa-\mathrm{B}$; AP-1, activator protein 1; LUC, luciferase; RIP-1, receptor-interacting serine/threonine-protein kinase 1; VEGF-C, vascular endothelial growth factor-C.

to increase the luciferase activity of the pGL3B-332 promoter. These results further indicate that RIP-1 regulates the luciferase activity of the VEGF-C promoter through NF- $\kappa B$ and AP-1.

The transcription factors $N F-\kappa B$ and $A P-1$ regulate the luciferase activity of the VEGF-C promoter. To investigate the effect of the transcription factors NF- $\mathrm{KB}$ and AP-1 on the
VEGF-C promoter, NF- $\kappa$ B and AP-1 eukaryotic expression vectors, pcDNA3.1-NF- $\kappa$ B and pcDNA3.1-AP-1 plasmids, were constructed. The knockdown interference RNA sequences, NF- $\kappa B-s i R N A$ and AP-1 siRNA, were also synthesized. After the pcDNA3.1-NF- $\kappa$ B and pcDNA3.1-AP-1 plasmids were transfected into $\mathrm{NOZ}$ cells for $48 \mathrm{~h}$, western blotting was used to test the protein expression of NF- $\mathrm{KB}$ and AP-1 in NOZ cells. As shown in Fig. 3A-D, NF- $\mathrm{kB}$ and AP-1 protein 
A

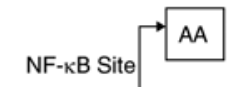

GAGGAGGCGAGGGAAOGGGAGCTCOAGGAGACGGCTTCCGAGGGAGAGTAGAG GGGAGGGCAGCCCGGGCTCGGCACGCTCCCTCCCTCGGCCGCTTTCTCTCACATAAG Two AP-1 Sites $\longrightarrow$ TTT

CGCAGGCAGAG GGCGCGTCAGTCATGCCCTGCCCCTGCGCCCGCCGCCGCCGCCGCC GCCGCTCAGCCCGGCGCGCTCTGGAGGATCCTGCGCCGCGGCGCTCCCGGGCCCCGC CGCCGCCAGCCGCCCCGCCGCCCTCCTCCCGCCCCCGGCACCGCCGCCAGCGCCCCC GCCGCAGCGCCCGCGGCCCGGCTCCTCTCACTTCGGGGAAGGGGAGG $\rightarrow$ Transcription

$+1$

C
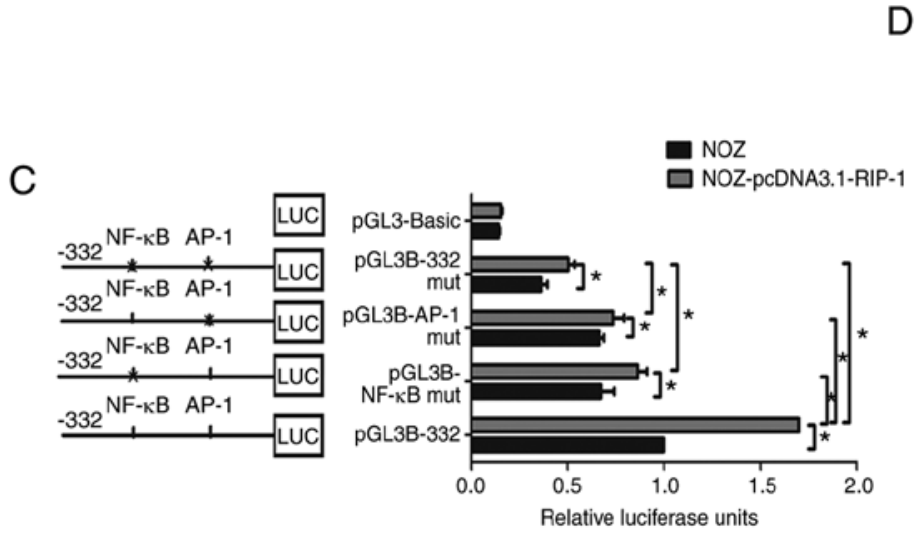

B

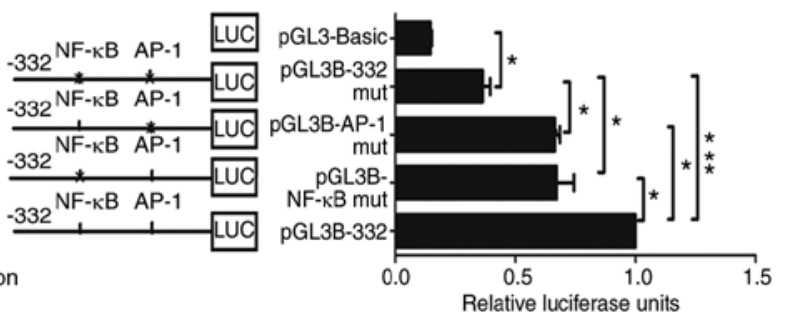

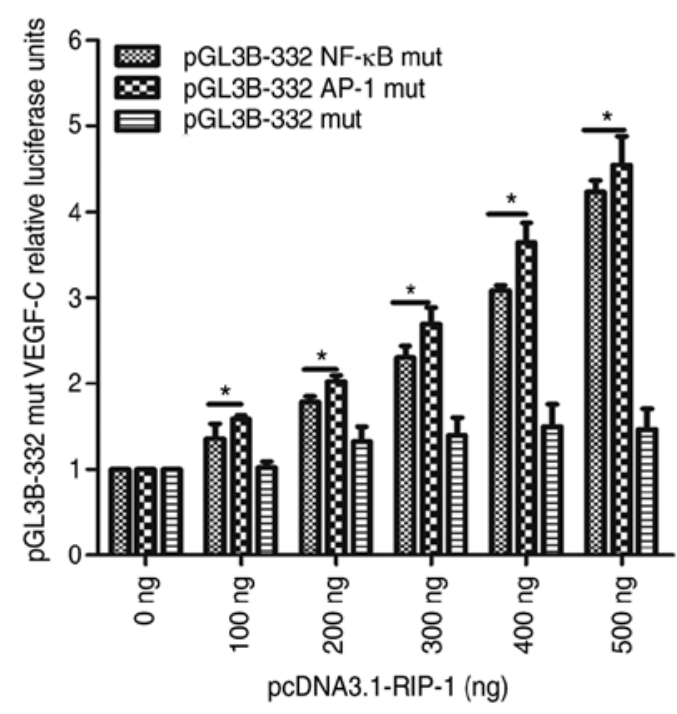

Figure 2. NF- $\kappa$ B and AP-1 sites were crucial for the pGL3B-332 relative luciferase activities. (A) Nucleotide sequence of the -332 to +1 nt fragment of the VEGF-C promoter. The promoter start site is $\mathrm{G}$ and $\mathrm{G}$ is set to +1 . The NF- $\mathrm{B}$ binding sites and the AP-1 binds sites in the nucleotide region are framed. The nucleotides in boxes next to arrows are the mutated oligonucleotides. AP-1 sites include two overlapping AP-1 binding sites (one site in a box, the other site underlined). (B) Luciferase activity analysis of VEGF-C promoter following the co-transfection of pRL-TK plasmids and mutated plasmids into NOZ cells with. pGL3-Basic vector served as the negative control. (C) pcDNA3.1-RIP-1 plasmid was co-transfected into NOZ cells with pGL3B-NF- $\kappa$ B mut, pGL3B-AP-1 mut or pGL3B-332 mut plasmids. (D) NOZ cells were treated with different concentrations of pcDNA3.1-RIP-1, and then the cells were co-transfected with the pRL-TK plasmid and the pGL3B-NF- $\kappa$ B mut, pGL3B-AP-1 mut or pGL3B-332 mut plasmid. The relative luciferase units were tested after 48 h. ${ }^{*} \mathrm{P}<0.05,{ }^{* * *} \mathrm{P}<0.001$ as indicated. Each transfection was carried out in duplicate and the data were expression as the mean \pm standard deviation of

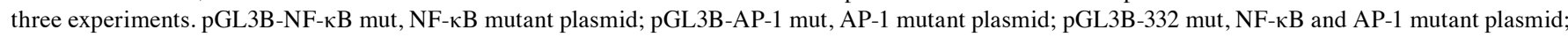
mut, mutant; NF- $\kappa \mathrm{B}$, nuclear factor $\kappa-\mathrm{B}$; AP-1, activator protein 1; LUC, luciferase; RIP-1, receptor-interacting serine/threonine-protein kinase 1; VEGF-C, vascular endothelial growth factor-C.

expression significantly increased in the pcDNA3.1-NF- $\kappa \mathrm{B}$ and pcDNA3.1-AP-1 groups compared with the control group (pcDNA-3.1). It was also found the luciferase activity of pGL3B-332 was significantly increased when co-transfected with pcDNA3.1-NF- $\kappa$ B or pcDNA3.1-AP-1 compared with the control group (Fig. 3E).

Furthermore, NF- $\mathrm{BB}$-siRNA and AP-1-siRNA were transfected into NOZ cells to knockdown the endogenous NF- $\kappa$ B and AP-1 proteins. After $48 \mathrm{~h}$, the proteins were harvested, and western blotting was performed to detect the protein expression of $N F-\kappa B$ and AP-1. The protein expression of $N F-\kappa B$ and AP-1 was significantly downregulated in NOZ cells compared with the control group (Fig. 3F-I). NF- $\kappa$ B-siRNA and AP-1-siRNA were then co-transfected into NOZ cells with pGL3B-332. The luciferase activity of pGL3B-332 was significantly decreased with NF-кB-siRNA and AP-1-siRNA compared with the control group (Fig. 3J).

As shown in Fig. 3K, the change in pGL3B-332 promoter luciferase activity was pcDNA3.1-NF- $\kappa$ B plasmid concentration-dependent as 200-500 ng pcDNA3.1-NF-кB plasmid significantly increased luciferase activity compared with the control group. However, the pGL3B-332-NF-кB mut plasmid's promoter luciferase activity did not significantly increase. In addition, pGL3B-332 and pGL3B-332-AP-1 mut plasmids were co-transfected with pcDNA3.1-AP-1 into the NOZ cells to analyze the change in luciferase activity. The activity of the pGL3B-332 promoter was enhanced in a pcDNA3.1-AP-1 concentration-dependent manner compared with the control group. However, the pGL3B-332-AP-1 mut promoter's luciferase activity was not markedly enhanced (Fig. 3L). These results show that the transcription factors NF- $\kappa$ B and AP-1 regulate the luciferase activity of the VEGF-C promoter.

RIP-1 promotes the binding of $N F-\kappa B$ and $A P-1$ to the $V E G F-C$ promoter. The effects of $\mathrm{NF}-\kappa \mathrm{B}$ and $\mathrm{AP}-1$ on the VEGF-C promoter were further confirmed by EMSA of nuclear extracts from NOZ cells. The results revealed that the nuclear extract could change the position of the biotin-labeled $\mathrm{NF}-\kappa \mathrm{B}$ and AP-1 probe in electrophoretic mobility, due to DNA and protein complex formation (bar 1 and 2; Fig. 4A and B). The RIP-1 overexpression plasmid increased the combined rates of the nuclear extract, and the NF- $\kappa \mathrm{B}$ and AP-1 binding sites, which were included in the nucleotide sequences of the biotin-labeled probe (bar 3; Fig. 4A and B). 

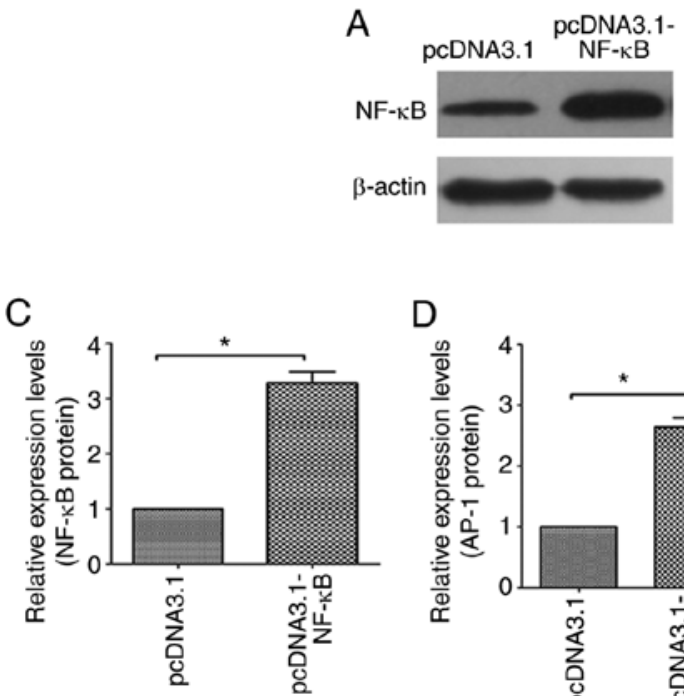

$\mathrm{F}$
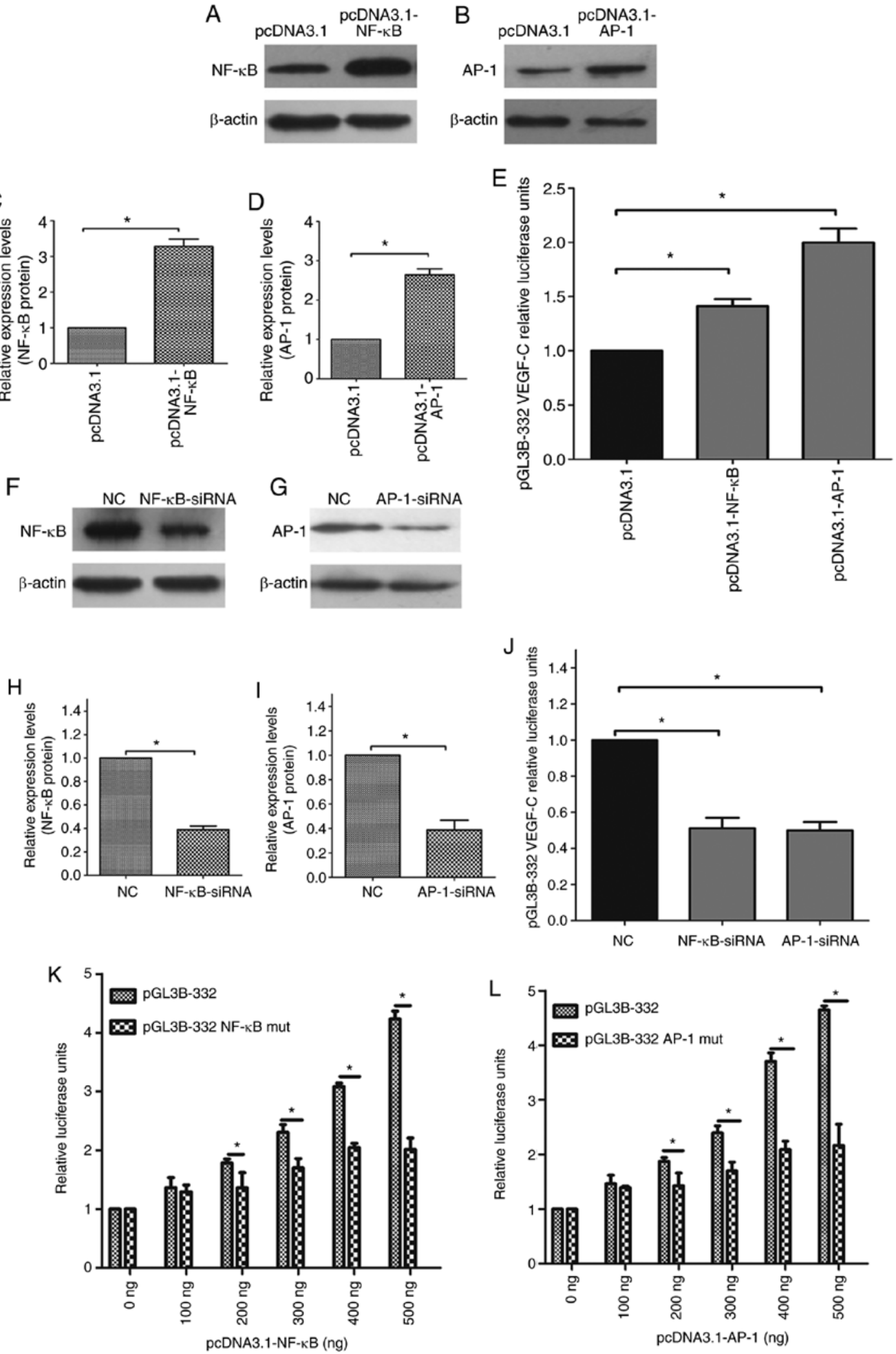

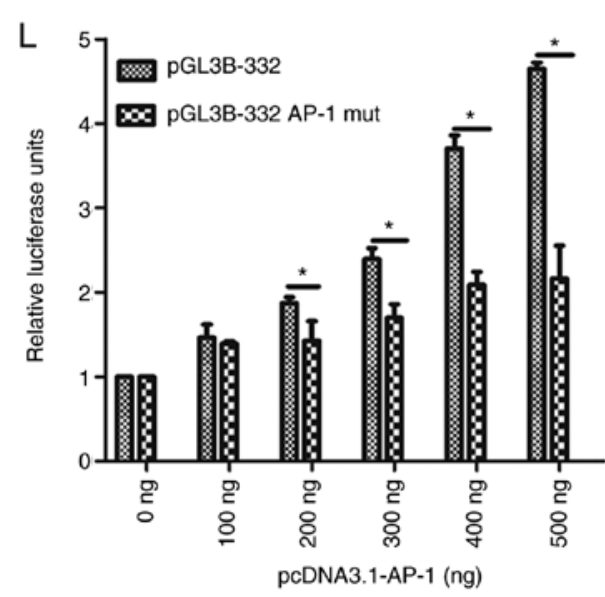

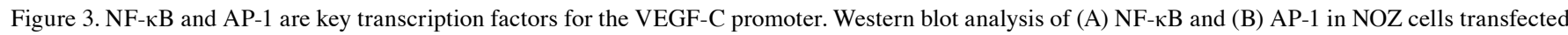
with pcDNA3.1-NF- $\mathrm{kB}$, pcDNA3.1-AP-1 or an empty pcDNA3.1 vector. Quantification of relative (C) NF- $\mathrm{kB}$ and (D) AP-1 protein expression levels in the NOZ cells. "P<0.05 vs. empty pcDNA3.1. (E) Luciferase activity analysis of VEGF-C promoter following the co-transfection of the pGL3B-332 plasmid and different pcDNA3.1 plasmids. pRL-TK plasmids were used for normalization. ${ }^{*} \mathrm{P}<0.05$ as indicated. (F) NF- $\mathrm{kB}$ and (G) AP-1 in NOZ cells transfected with NF-kB-siRNA, AP-1-siRNA or an NC siRNA. Quantification of relative (H) NF- $\mathrm{kB}$ and (I) AP-1 protein expression levels in the NOZ cells. "P<0.05 vs. NC. (J) Luciferase activity analysis of VEGF-C promoter following the co-transfection of the pGL3B-332 plasmid and different siRNAs. ${ }^{*} \mathrm{P}<0.05$ as indicated. (K) VEGF-C promoter luciferase activity following the co-transfection of NOZ cells with the pGL3B-332 or pGL3B-332 NF-кB mut plasmid and different concentrations of pcDNA3.1-NF- $\mathrm{KB}$. (L) VEGF-C promoter luciferase activity following the co-transfection of NOZ cells with the pGL3B-332 or pGL3B-332 AP-1 mut plasmid and different concentrations of pcDNA3.1-AP-1. The experiments were duplicated three times. ${ }^{*} \mathrm{P}<0.05$ as indicated. pcDNA3.1, overex-

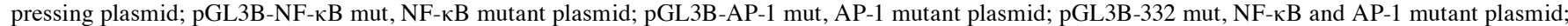
mut, mutant; NF- $\mathrm{kB}$, nuclear factor $\kappa-\mathrm{B}$; AP-1, activator protein 1; VEGF-C, vascular endothelial growth factor-C; NC, negative control siRNA. 
A

$\begin{array}{rcccccc}\text { Biotin-labeled probe } & + & + & + & + & + \\ \text { Cold probe } & - & - & - & + & - \\ \text { Cold mutated probe } & - & - & - & - & + \\ \text { Nuclear exact } & - & + & + & + & + \\ \text { pcDNA3.1-RIP-1 } & - & - & + & - & -\end{array}$
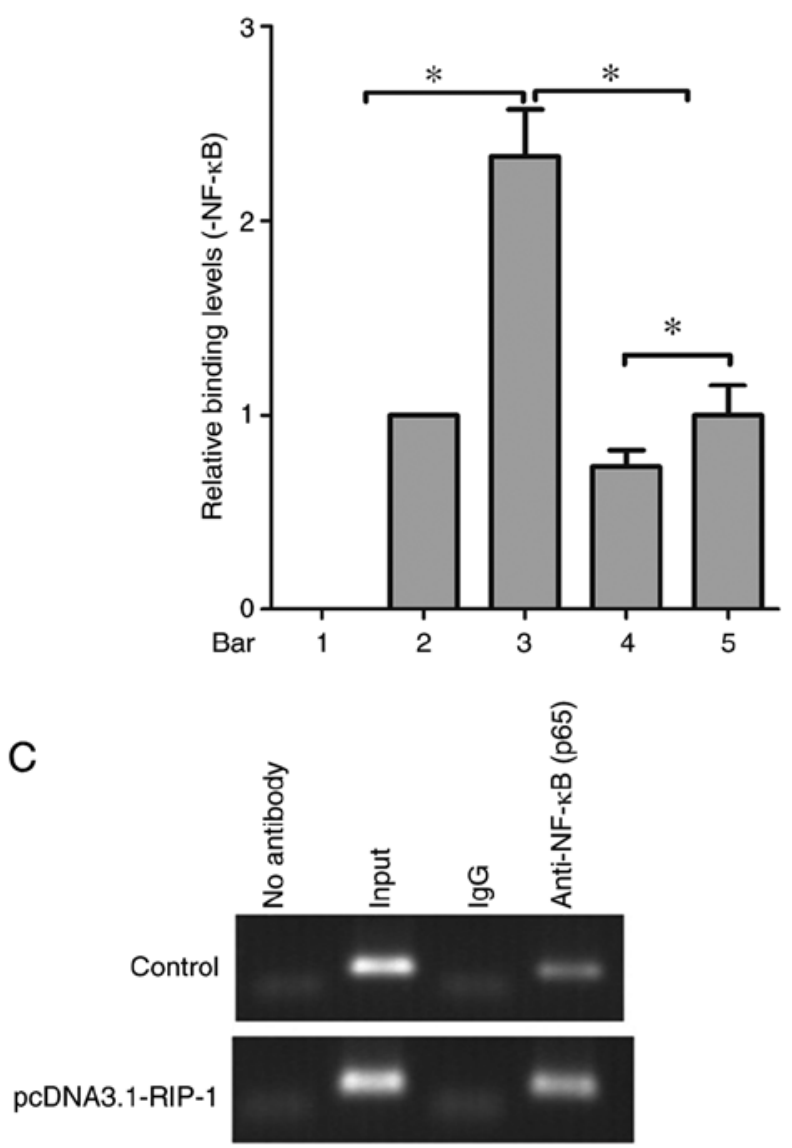

B $\begin{array}{rccccc}\text { Biotin-labeled probe } & + & + & + & + & + \\ \text { Cold probe } & - & - & - & + & - \\ \text { Cold mutated probe } & - & - & - & - & + \\ \text { Nuclear exact } & - & + & + & + & + \\ \text { pcDNA3.1-RIP-1 } & - & - & + & - & -\end{array}$

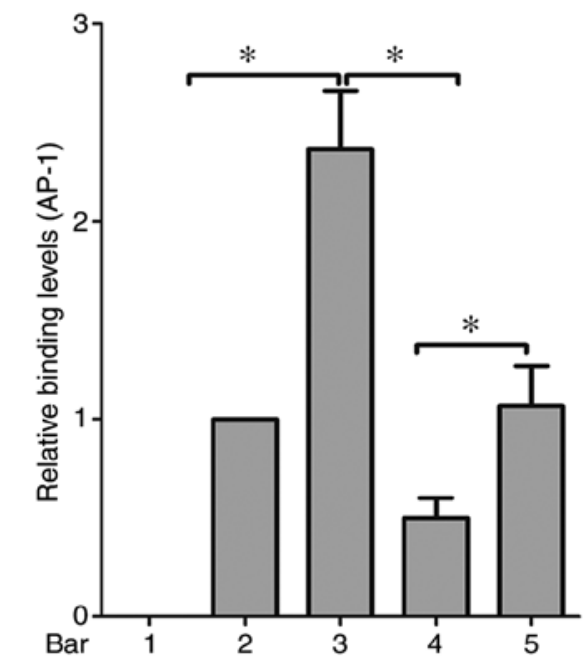

$\mathrm{D}$

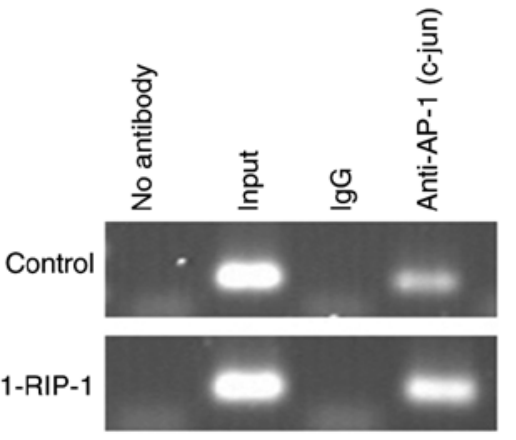

Figure 4. A transcription factor binding site in VEGF-C promoter is regulated by RIP-1. Electrophoretic mobility shift assay of (A) NF- $\mathrm{B}$ and (B) AP-1. The 5 -biotin end-labeled probe were incubated in the absence (bar 1) or presence (bar 2) of nuclear proteins from NOZ cells. The probe was also incubated in the presence of nuclear proteins from NOZ cells, which were transfected with the pcDNA3.1-RIP plasmid (bar 3). The cold, unlabeled probe, (bar 5) and cold mutated probe (bar 4) were used as competitors at a concentration of 100 -fold molar excess to the 5'-biotin end-labeled probe. ${ }^{*} \mathrm{P}<0.05$ as indicated. Chromatin immunoprecipitation assay of chromatin from NOZ cells immunoprecipitated with (C) anti-NF- $\mathrm{KB}$ and (D) anti-AP-1 antibodies. The total extracted DNA was set as the input prior to immunoprecipitation and the immunoprecipitated samples were PCR-amplified using primers specific to a region that included the NF-kB and AP-1 binding sites in the VEGF-C promoter. Normal rabbit IgG antibodies or a sample without antibodies were used as controls. Chromatin immunoprecipitation assay were performed twice. pcDNA3.1-RIP, RIP-1 overexpressing plasmid; NF- $\mathrm{B}$, nuclear factor $\kappa-\mathrm{B}$; AP-1, activator protein 1; VEGF-C, vascular endothelial growth factor-C; RIP-1, receptor-interacting serine/threonine-protein kinase 1; IgG, immunoglobulin G.

In addition, a competition assay showed that pre-incubation with a 100 -fold molar excess of cold probe diminished the intensity of the bands, but the cold mutated probes did not (bars 4 and 5; Fig. 4A and B).

To investigate whether $\mathrm{NF}-\kappa \mathrm{B}$ and $\mathrm{AP}-1$ are associated with the VEGF-C promoter in vivo, ChIP experiments using either NF- $\kappa$ B or AP-1 antibodies and PCR amplification were performed. As shown in Fig. 4C and D, 112 and 120 bp DNA fragments covering NF- $\kappa \mathrm{B}$ and AP-1 sites in the VEGF-C promoter were amplified, and chromatin was immunoprecipitated with anti-NF- $\kappa \mathrm{B}$ or anti-AP-1 antibodies. In addition, RIP-1-promoted NF- $\kappa$ B and AP-1 bound to the VEGF-C promoter. The same bands were obtained with DNA input, and the normal IgG and no antibody controls did not give rise to the immunoprecipitation of DNA fragments. This was found by PCR amplification using two assays.

In conclusion, these results suggest that RIP-1 stimulates the transcription factors NF- $\mathrm{B}$ and AP-1 to bind directly to their corresponding consensus binding sites in the VEGF-C promoter region.

Establishment of the orthotopic xenograft nude mouse model of gallbladder cancer. In our previous experiments, the authors established the mouse model of subcutaneous tumors, which cannot illustrate the biological function of the RIP-1 gene in lymph node metastasis (6). In the current study, the authors therefore tried to establish the mouse model of orthotopic gallbladder cancer tumors using modified methods (Fig. 5). 
Table II. RIP-1 silencing inhibits the progression of orthotopic xenograft nude mice models.

\begin{tabular}{lccc}
\hline Condition & NOZ-RIPsi group & NOZ-NC group & NOZ-con group \\
\hline Tumors formation & $4 / 5(80)$ & $4 / 5(80)$ & $5 / 5(100)$ \\
Liver metastasis & $1 / 5(20)$ & $4 / 5(80)^{\mathrm{a}}$ & $5 / 5(100)^{\mathrm{a}}$ \\
Ascites & $0 / 5(0)$ & $4 / 5(80)^{\mathrm{a}}$ & $5 / 5(100)^{\mathrm{a}}$ \\
Lymph node metastasis & $0 / 5(0)$ & $4 / 5(80)^{\mathrm{a}}$ & $5 / 5(100)^{\mathrm{a}}$ \\
Lung metastasis & $0 / 5(0)$ & $0 / 5(0)$ & $0 / 5(0)$
\end{tabular}

${ }^{\mathrm{a}} \mathrm{P}<0.05$ vs. NOZ-RIPsi group. Values are expressed as no. with condition/total no. (percentage). RIP or RIP-1, receptor-interacting serine/threonine-protein kinase 1; si, small interfering; NC, negative control; con, untransfected NOZ cells.

The mouse model was successfully established by using NOZ cells and found that there were notable swollen lymph nodes on the hepatoduodenal ligament. These were detected as mostly positive by pathology (Figs. 6F, 7A and 7B). As shown in Fig. 7B, the lymph nodes were occupied by a large amount of tumor cells. NOZ-con, NOZ-NC and NOZ-RIPsi were orthotopically xenografted into the gallbladder of nude mice. Post-inoculation, these mice were raised in a barrier system for 5 weeks. Some mice showed dyscrasia, and large tumors could be seen and touched in the abdomens of the mice (Fig. 6A and B). When mice were sacrificed, five of the four mice in the NOZ-con and NOZ-NC group tumors had developed ascites, whereas none of the NOZ-RIPsi group mice had ascites at the time of sacrifice (Fig. 6C and Table II). Fig. 6D showed the hemorrhagic ascites of the mice at the time of autopsy. Hepatic metastasis or invasion were macroscopically found in the livers of five mice in the NOZ-con group and four in the NOZ-NC group, but only one mouse had liver metastasis in the NOZ-RIPsi group (Figs. 6E and 7C, and Table II). Five mice in the NOZ-con group, four mice in the NOZ-NC group and no mice in the NOZ-RIPsi group had lymph node metastasis (Figs. 6F and 7A, and Table II). No lung metastasis was detected in all three groups (Table II).

RIP-1 inhibition downregulates the expression of VEGF-C in orthotopic xenograft gallbladder cancer in nude mouse models. The expression of RIP-1 in all three groups of orthotopic xenograft gallbladder tumors was analyzed. Compared with the NOZ-con group $(0.261 \pm 0.043)$ and the NOZ-NC group (0.238 \pm 0.027$)$, the expression level of RIP-1 was significantly decreased in the NOZ-RIPsi group $(0.182 \pm 0.015$; Fig. 8A). Consistent with the expression of RIP-1, the VEGF-C expression level was significantly lower in the NOZ-RIPsi group $(14.12 \pm 2.26)$ than in the NOZ-con $(21.61 \pm 1.52)$ and NOZ-NC groups (21.18 \pm 2.57 ; Fig. 8B).

RIP-1 inhibition downregulates the microlymphatic vessel density $(M L V D)$ in the xenograft tumor of gallbladder cancer. The microlymphatic vessels of xenograft tumors of gallbladder cancer were marked by LYVE-1 antibodies using the immunohistochemical method. Of note, some tumor cells could be found in the middle of brown-stained endothelial cell clusters (Fig. 7D). The MLVD of orthotopic xenograft tumors in the NOZ-RIPsi group (25.24 \pm 2.87$)$ was significantly lower than in the NOZ-con

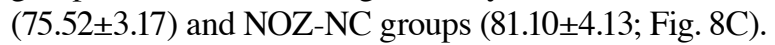

\section{Discussion}

Previous research has shown that RIP-1 was convened quickly with FADD and TRAF2 when TNF- $\alpha$ binds to tumor necrosis factor receptor superfamily member $1 \mathrm{~A}$ (TNFR1), a TNF- $\alpha$ receptor, and is a key molecule of the TNF- $\alpha$-TNFR1 signal pathway (25). Some studies have demonstrated that RIP-1 plays a vital role in this pathway and is essential in promoting the survival of inflammatory and immune cells (26-28).

In our previous study, the authors confirmed that RIP-1 was highly expressed in gallbladder cancer tissues, and RIP-1 expression is significantly correlated with the clinical stage and lymph node metastasis in patients with gallbladder carcinoma (6). This revealed that RIP-1 could promote tumor growth and invasion (6). Experiments on the underlying mechanism of tumor growth and invasion by RIP-1 showed that RIP-1 silencing could decrease the expression of VEGF-C in NOZ cells (6). These were consistent with previous studies $(6,29,30)$. Han et al (29) and Azijli et al (30) have performed research on leukemia and lung cancer cell lines, respectively. They found that RIP-1 could promote the survival, proliferation, and migration of leukemia and lung cancer.

VEGF-C is part of the VEGF family, which is correlated with lymph node metastasis in many cancers, such as gastric cancer (31) and lung cancer (32). Since the lymphatic endothelial cell-specific antibodies (LYVE-1 and D2-40) were found, more studies have suspected that VEGF-C could induce microlymphangiogenesis and lymph metastasis $(24,33)$. In addition, VEGF-C plays a very important role in tumor proliferation and invasion $(34,35)$. Lymph metastasis is the most important means of gallbladder cancer diffusion (36). Previous research by our group has reported that VEGF-C promotes growth and invasion in gallbladder cancer (37).

In mammals, tens of thousands of non protein-coding and protein-coding genes are regulated in specific manners (38). These genes are primarily regulated in combination via the interaction of a specific set of transcription factors with their cognate cis-regulatory elements (38). Thus, in the present study, the authors investigated the specific mechanisms by which RIP-1 regulates VEGF-C expression.

The authors constructed the various fragments of the VEGF-C promoter for a more precise location, and found that -332 to $-190 \mathrm{nt}$ contained the largest relative luciferase activity within the VEGF-C promoter. This suggested that this is the core region of the VEGF-C promoter. Using 

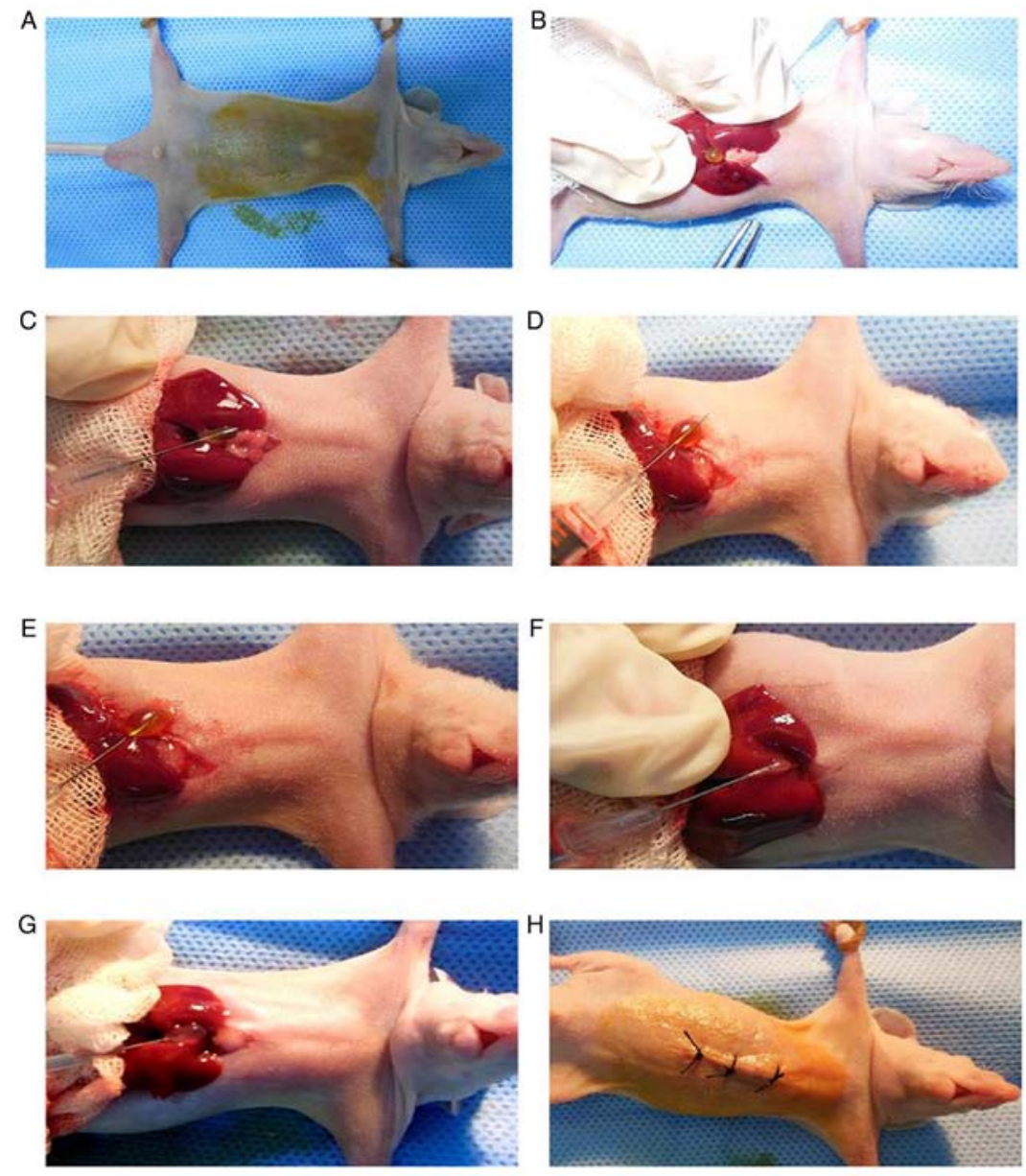

Figure 5. Establishment of the orthotopic xenograft model using modified methods. (A) Anesthesia, fixation and complexing iodine sterilization of mouse skin (B) Exposed gallbladder of the nude mice. (C) The needle of an insulin syringe punctured the gallbladder. (D) Needle pushed through the gallbladder, piercing the other side. (E) Needle withdrawn back into the gallbladder. (F) Removal of the gallbladder bile. (G) Cells suspension mixed with Matrigel was injected into the empty gallbladder slowly. (H) The sutured abdominal wall.

bioinformatics software, two overlapping AP-1 sites were found (GGCGCGTCAGT and CGTCAGTCATG at -207 to -192 bp overlapped to form GGCGCGTCAGTCATG) in the area of -332 to $-190 \mathrm{nt}$, which could regulate the activity of the VEGF-C promoter. The NF- $\mathrm{B}$ (GGGGAGCTCC) and AP-1 sites were confirmed and may be crucial for VEGF-C promoter activity. The authors also demonstrated that the transcription factors $\mathrm{NF}-\kappa \mathrm{B}$ and AP-1 could bind to the -332 to $-190 \mathrm{nt}$ region of the VEGF-C promoter using in vitro EMSA and ChIP assays. However, the $-1,000$ to $-487 \mathrm{nt}$ region of the VEGF-C promoter had noticeably increased relative luciferase activity, which was even higher than the full length of the VEGF-C promoter. This could potentially be due to some inhibiting factors binding to the $-1,000$ to $-487 \mathrm{nt}$ region.

The pGL3B-332 plasmid was then chosen to conduct further research. Different concentrations of pcDNA3.1-RIP-1 were transfected into NOZ cells, and it was found that the relative luciferase activity of pGL3B-332 increased with increasing pcDNA3.1-RIP-1 plasmid concentration. When transfecting pGL3B-332, pGL3B-NF- $\kappa$ B mut (NF- $\kappa$ B site mutation), pGL3B-AP-1 mut (AP-1 site mutation), and pGL3B-332 mut (NF- $\kappa \mathrm{B}$ and AP-1 sites co-mutation) into NOZ cells, NF- $\mathrm{NB}$ and AP-1 site mutation markedly decreased the relative luciferase activity of the pGL3B-332 VEGF-C promoter. These results also showed that NF- $\kappa \mathrm{B}$ and AP-1 sites were crucial for VEGF-C promoter activity. Further, when endogenic NF- $\kappa \mathrm{B}$ and AP-1 were overexpressed or silenced in NOZ cells, the relative luciferase activity of the pGL3B-332 promoter fragment increased with the increasing amounts of $N F-\kappa B$ and AP-1 protein expression. Together, the authors confirmed that RIP-1 could activate the transcription factors NF- $\kappa$ B and AP-1 to combine with the -332 to $-190 \mathrm{nt}$ region of the VEGF-C promoter, hence enhancing the promoter's activity.

In a previous study by our group, a subcutaneous xenograft nude mouse model of gallbladder cancer was built and silencing the expression of RIP-1 by a siRNA was observed to inhibit the growth of subcutaneous xenograft tumors (6). However, liver, lung, and lymph node metastases were not observed, and ascites had not developed (6). A study demonstrated that carcinoma in the human gallbladder showed significant invasive growth, irregular shape and unclear boundaries (15). However, the subcutaneous xenograft model cannot simulate the microenvironment of gallbladder cancer growth (15). Therefore, a previous study by our group demonstrated that orthotopic xenograft models of gallbladder cancer are better than subcutaneous xenograft gallbladder cancer models for studying the biological characteristics of gallbladder cancer (16). 

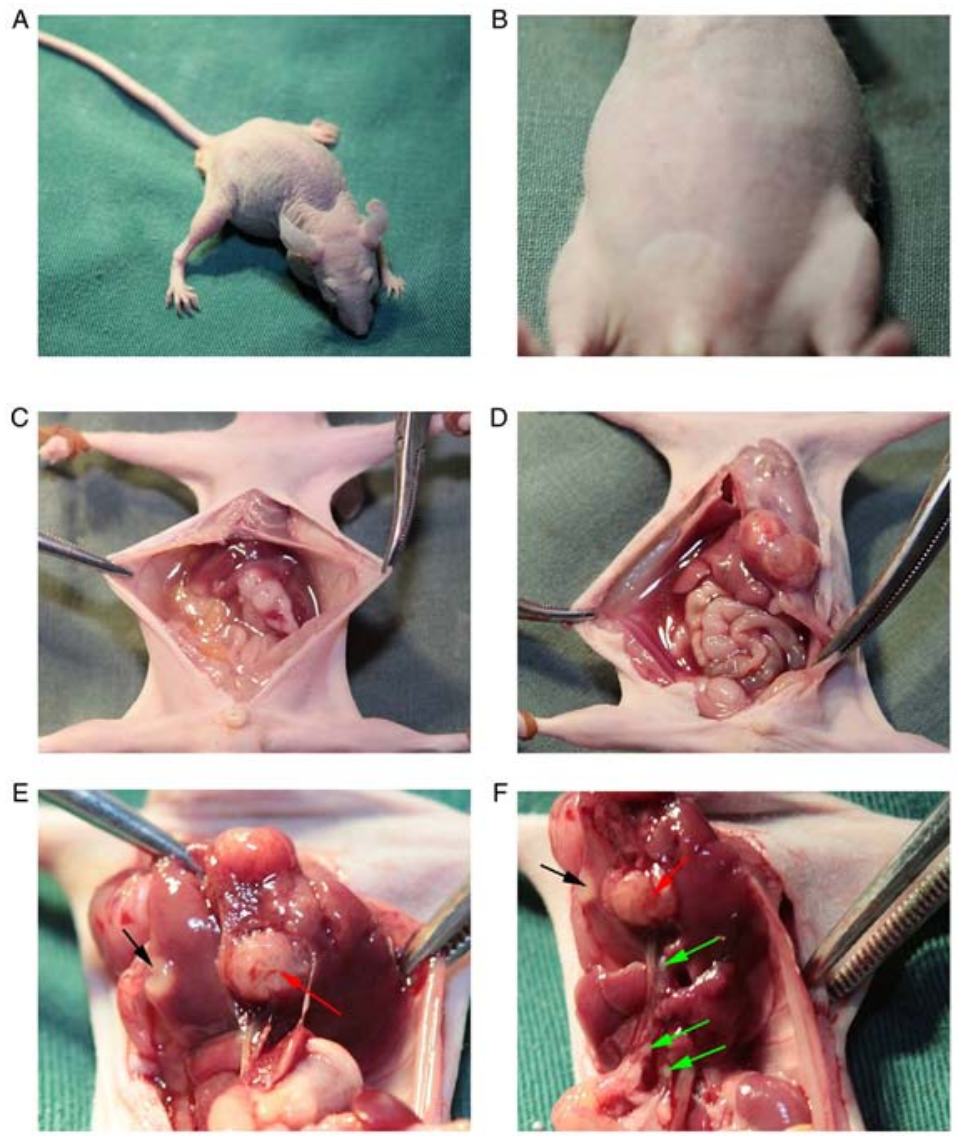

Figure 6. Cachexia, ascites, hepatic invasion and lymph node metastasis are observed in the mouse model of orthotopic gallbladder cancer. The presence of (A) cachexia, (B) palpable ascites in the mouse model. (C) The presence of internal ascites in the mouse model. (D) Hemorrhagic ascites in the mouse model (E) The presence of hepatic invasion in the mouse model. (F) Lymph node metastasis in the hepatoduodenal ligament of mice. Green arrows mark the enlarged lymph node. Black arrows mark the invasive tumor in the liver of mice. Red arrows mark the tumor in the gallbladder.
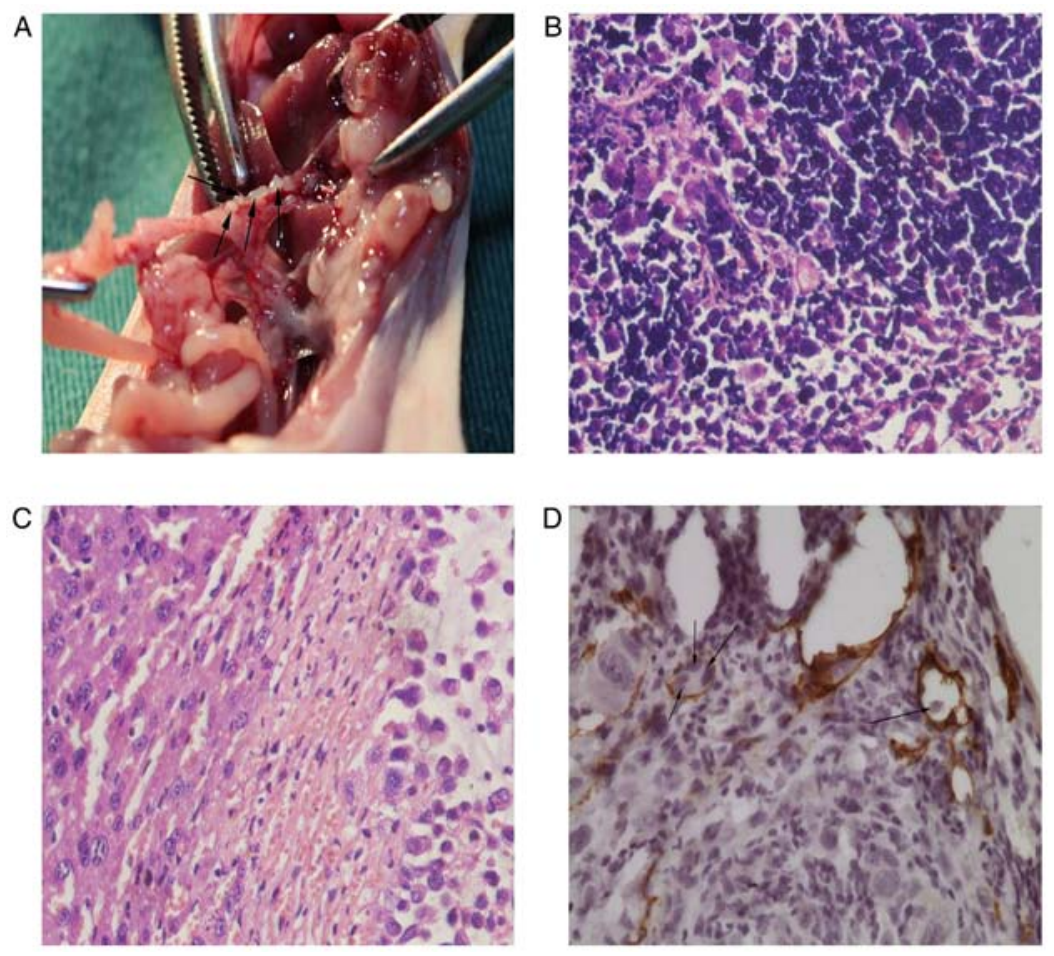

Figure 7. Receptor-interacting serine/threonine-protein kinase 1 promotes gallbladder cancer lymph metastasis in the mouse model of orthotopic gallbladder cancer. (A) Lymph node metastasis in the hepatoduodenal ligament of mice. Black arrows mark the enlarged lymph nodes. Hematoxylin and eosin staining of the (B) lymph nodes and (C) the liver of orthotopic model mice. (D) Immunohistochemical detected with anti-mouse lymphatic vessel endothelial hyaluronic acid receptor 1 antibodies. Brown areas show the lymph tube or the lymphatic endothelial cells. Black arrows show the tumor cells in the lymph tube. 
A
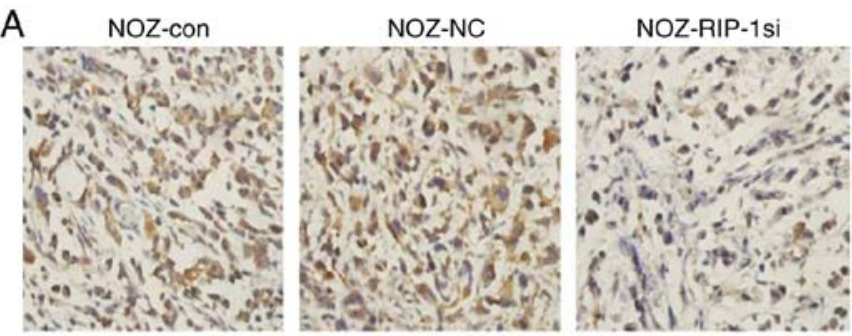

B
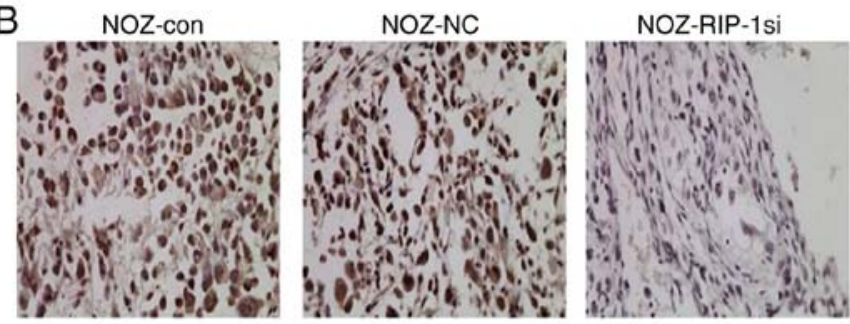

C

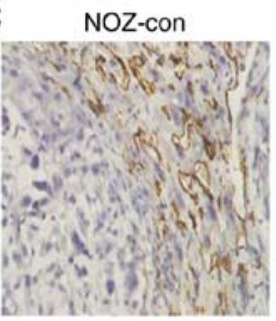

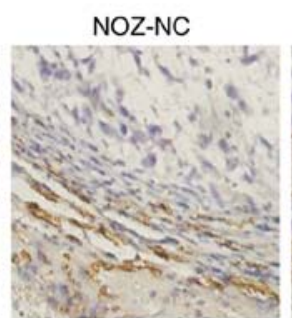

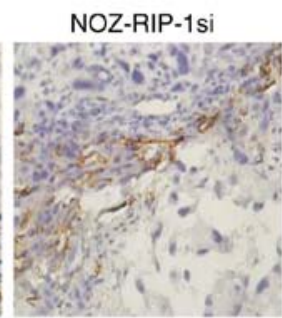

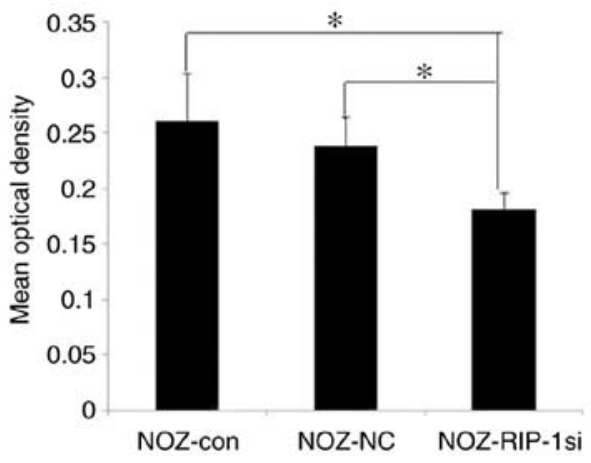
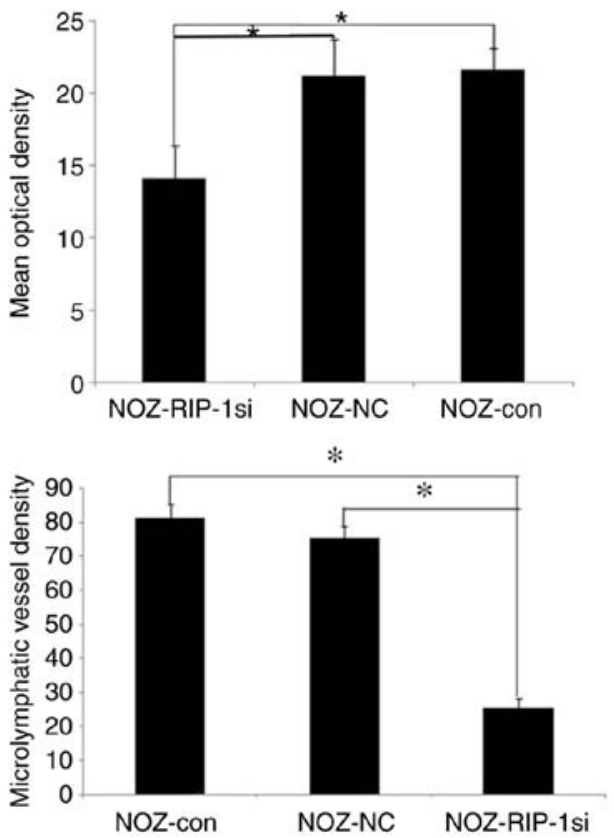

Figure 8. RIP-1 promotes gallbladder cancer microlymphangiogenesis in the mouse model of orthotopic gallbladder cancer. Immunohistochemical analysis of mice models of orthotopic xenograft gallbladder cancer and microlymphatic vessel density. Immunohistochemical analysis of the expression of (A) RIP-1 and (B) VEGF-C in mice treated with untransfected, NC-transfected or RIPsi-transfected NOZ cells. Magnification, x400. The bar graphs show the quantitative evaluation of (A) RIP-1 and (B) VEGF-C expression. Bars represent the mean optical density \pm standard deviation. (C) Representative lymphatic vessel endothelial hyaluronic acid receptor 1 staining in microlymphatic vessels of mice treated with untransfected, NC-transfected or RIPsi-transfected NOZ cells. The bar graph shows the quantitative evaluation of the results and bars represent the mean microlymphatic vessel density \pm standard deviation. ${ }^{*} \mathrm{P}<0.05$ as indicated. RIP-1, receptor-interacting serine/threonine-protein kinase 1; VEGF-C, vascular endothelial growth factor-C; RIPsi, siRNA against RIP-1; con, untreated NOZ cells; NC, negative control siRNA.

In a previous orthotopic gallbladder cancer nude mouse models by our group, there were many faults, such as the anesthesia method and the method for emptying bile (16). In the present study, the anesthesia method was modified, using a mixed anesthetic instead of chloraldurate. The gallbladder of a nude mouse is very small and sometimes finding it can be difficult. In a previous by our group, the bile was removed using a syringe needle that punctured the gallbladder. Then the needle re-entered the gallbladder, which was very difficult. The described procedure could result in unsuccessful model establishment. Therefore the procedure was modified in the current study. The needle was used to puncture through the gallbladder and then withdrawn back in to the gallbladder, leaving a hole on one side. After the bile was swabbed, the cells were injected into the empty gallbladder. Thus the needle was not removed from the gallbladder until the end of the procedure. The modified method increased the success rate of the establishment of the orthotopic nude mouse model of gallbladder cancer.
In the animal model of gallbladder cancer, the authors observed that interference of RIP-1 by an siRNA suppressed the progression of the orthotopic gallbladder cancer xenograft tumor, consistent with a previous study by our group (6). It was also found that RIP-1 knockdown significantly reduced lymphangiogenesis in the mouse model of gallbladder cancer. Immunohistochemical analysis found that the expression level of RIP-1 was notably decreased in the NOZ-RIPsi group. The RIP-1 and VEGF-C expression level was lower in the NOZ-RIPsi group, which was consistent with a previous in vitro study (6). These results are also consistent with studies on the functions of RIP-1 in other cancers $(7,29,30)$, suggesting that RIP-1 played a vital role in promoting the tumor progression. The mouse model established in the current study conformed to the natural metastasis of gallbladder cancer in vivo, in accordance with the theory proposed by Fidler (39). In the orthotopic transplantation model, the tumor could display its natural biological characteristics (16). The authors of the current study successfully established the orthotopic 
mouse model of gallbladder cancer tumors, in addition to the lymph node metastasis mouse model. The results suggest that RIP-1 downregulation can inhibit gallbladder cancer growth and lymphatic metastasis in gallbladder cancer.

In conclusion, the current study researched the mechanisms of RIP regulating VEGF-C, and further demonstrated that RIP-1 promotes lymphatic metastasis in gallbladder cancer. The -332 to $-190 \mathrm{nt}$ region was the critical area for VEGF-C promoter activity. Two overlapping AP-1 sites and one $\mathrm{NF}-\kappa \mathrm{B}$ site in the -332 to $-190 \mathrm{nt}$ region were also located, which could mediate the activity of the VEGF-C promoter. In addition, it was confirmed that RIP-1 could activate the transcription factors $\mathrm{NF}-\kappa \mathrm{B}$ and $\mathrm{AP}-1$ to bind to the -332 to $-190 \mathrm{nt}$ area, enhancing the activity of the VEGF-C promoter. The authors of the current study successfully established an orthotopic mouse model of gallbladder cancer tumors by modified methods and established the lymph node metastasis mouse model. The model revealed that downregulation of RIP-1 can decrease lymphangiogenesis and lymphatic metastasis markedly, which could be a potential therapeutic target for gallbladder cancer.

\section{Acknowledgements}

Not applicable.

\section{Funding}

The current study was supported by grants from the National Natural Science Foundation of China (grant nos. 81672468 and 81272373) and the National Clinical Key Specialty Construction Project (General Surgery) of China (grant no. 2012).

\section{Availability of data and materials}

The datasets used and/or analyzed during the current study are available from the corresponding author on reasonable request.

\section{Authors' contributions}

YC, FS and GZ conceived and designed the study. GZ, QD and $\mathrm{XC}$ performed the experiments. NT and XW interpreted the results. GZ and $\mathrm{XC}$ wrote the paper, but all authors contributed to writing. All authors read and approved the final manuscript.

\section{Ethics approval and consent to participate}

This study was approved by the Ethics Committee of the Medical Faculty of the Fujian Medical University.

\section{Patient consent for publication}

Not applicable.

\section{Competing interests}

The authors declare that they have no potential conflict of interest.

\section{References}

1. Bartlett DL, Fong Y, Fortner JG, Brennan MF and Blumgart LH: Long-term results after resection for gallbladder cancer. Implications for staging and management. Ann Surg 224: 639-646, 1996.

2. Cubertafond P, Gainant A and Cucchiaro G: Surgical treatment of 724 carcinomas of the gallbladder. Results of the French surgical association survey. Ann Surg 219: 275-280, 1994.

3. Randi G, Malvezzi M, Levi F, Ferlay J, Negri E, Franceschi S and La Vecchia C: Epidemiology of biliary tract cancers: An update. Ann Oncol 20: 146-159, 2009.

4. Shukla VK, Chauhan VS, Mishra RN and Basu S: Lifestyle, reproductive factors and risk of gallbladder cancer. Singapore Med J 49: 912-915, 2008.

5. Miller G and Jarnagin WR: Gallbladder carcinoma. Eur J Surg Oncol 34: 306-312, 2008.

6. Zhu G, Chen X, Wang X, Li X, Du Q, Hong H, Tang N, She F and Chen Y: Expression of the RIP-1 gene and its role in growth and invasion of human gallbladder carcinoma. Cell Physiol Biochem 34: 1152-1165, 2014.

7. Park S, Hatanpaa KJ, Xie Y, Mickey BE, Madden CJ,Raisanen JM, Ramnarain DB, Xiao G, Saha D, Boothman DA, et al: The receptor interacting protein 1 inhibits p53 induction through NF-kappaB activation and confers a worse prognosis in glioblastoma. Cancer Res 69: 2809-2816, 2009.

8. Hsu H, Huang J, Shu HB, Baichwal V and Goeddel DV: TNF-dependent recruitment of the protein kinase RIP to the TNF receptor-1 signaling complex. Immunity 4: 387-396, 1996.

9. Kelliher MA, Grimm S, Ishida Y, Kuo F, Stanger BZ and Leder P: The death domain kinase RIP mediates the TNF-induced NF-kappaB signal. Immunity 8: 297-303, 1998.

10. Hur GM, Lewis J, Yang Q, Lin Y, Nakano H, Nedospasov S and Liu ZG: The death domain kinase RIP has an essential role in DNA damage-induced NF-kappa B activation. Genes Dev 17: 873-882, 2003

11. Devin A, Lin Y and Liu ZG: The role of the death-domain kinase RIP in tumour-necrosis-factor-induced activation of mitogen-activated protein kinases. EMBO Rep 4: 623-627, 2003.

12. Liu ZG, Hsu H, Goeddel DV and Karin M: Dissection of TNF receptor 1 effector functions: JNK activation is not linked to apoptosis while NF-kappaB activation prevents cell death. Cell 87: 565-576, 1996.

13. Pacifico F and Leonardi A: NF-kappaB in solid tumors. Biochem Pharmacol 72: 1142-1152, 2006.

14. Zhu G, Du Q, Wang X, Tang N, She F and Chen Y: TNF- $\alpha$ promotes gallbladder cancer cell growth and invasion through autocrine mechanisms. Int J Mol Med 33: 1431-1440, 2014.

15. Horiuchi H, Kawamata H, Fujimori T and Kuroda Y: A MEK inhibitor (U0126) prolongs survival in nude mice bearing human gallbladder cancer cells with K-ras mutation: Analysis in a novel orthotopic inoculation model. Int J Oncol 23: 957-963, 2003.

16. Du Q, Jiang L, Wang XQ, Pan W, She FF and Chen YL: Establishment of and comparison between orthotopic xenograft and subcutaneous xenograft models of gallbladder carcinoma. Asian Pac J Cancer Prev 15: 3747-3752, 2014.

17. Homma S, Hasumura $\mathrm{S}$, Nagamori $\mathrm{S}$ and Kameda $\mathrm{H}$ : Establishment and characterization of a human gall bladder carcinoma cell line NOZ. Hum Cell 1: 95-97, 1988.

18. Heckman KL and Pease LR: Gene splicing and mutagenesis by PCR-driven overlap extension. Nat Protoc 2: 924-932, 2007.

19. Rettino A, Rafanelli F, Genovese G, Goracci M, Cifarelli RA, Cittadini A and Sgambato A: Identification of Spl and GC-boxes as transcriptional regulators of mouse Dag1 gene promoter. Am J Physiol Cell Physiol 297: C1113-C1123, 2009.

20. Wu YL, Peng XE, Wang D, Chen WN and Lin X: Human liver fatty acid binding protein (hFABP1) gene is regulated by liver-enriched transcription factors HNF3 $\beta$ and C/EBP $\alpha$. Biochimie 94: 384-392, 2012.

21. Ceelie H, Spaargaren-Van Riel CC, De Jong M, Bertina RM and Vos HL: Functional characterization of transcription factor binding sites for HNF1-alpha, HNF3-beta (FOXA2), HNF4-alpha, Sp1 and Sp3 in the human prothrombin gene enhancer. J Thromb Haemost. 1: 1688-1698, 2003.

22. Weidner N, Semple JP, Welch WR and Folkman J: Tumor angiogenesis and metastasis-correlation in invasive breast carcinoma. N Engl J Med 324: 1-8, 1991. 
23. Vermeulen PB, Gasparini G, Fox SB, Toi M, Martin L, McCulloch P, Pezzella F, Viale G, Weidner N, Harris AL and Dirix LY: Quantification of angiogenesis in solid human tumours: An international consensus on the methodology and criteria of evaluation. Eur J Cancer 32A: 2474-2484, 1996.

24. Du Q, Jiang L, Wang X, Wang M, She F and Chen Y: Tumor necrosis factor- $\alpha$ promotes the lymphangiogenesis of gallbladder carcinoma through nuclear factor- $\mathrm{B}$-mediated upregulation of vascular endothelial growth factor-C. Cancer Sci 105: 1261-1271, 2014.

25. O'Donnell MA and Ting AT: RIP1 comes back to life as a cell death regulator in TNFR1 signaling. FEBS J 278: 877-887, 2011.

26. Hitomi J, Christofferson DE, Ng A, Yao J, Degterev A, Xavier RJ and Yuan J: Identification of a molecular signaling network that regulates a cellular necrotic cell death pathway. Cell 135: $1311-1323,2008$

27. Ting AT, Pimentel-Muiños FX and Seed B: RIP mediates tumor necrosis factor receptor 1 activation of NF-kappaB but not Fas/APO-1-initiated apoptosis. EMBO J 15: 6189-6196, 1996

28. Devin A, Lin Y, Yamaoka S, Li Z, Karin M and Liu Z: The alpha and beta subunits of IkappaB kinase (IKK) mediate TRAF2-dependent IKK recruitment to tumor necrosis factor (TNF) receptor 1 in response to TNF. Mol Cell Biol 21: 3986-3994, 2001.

29. Han W, Xie J, Fang Y, Wang Z and Pan H: Nec-1 enhances shikonin-induced apoptosis in leukemia cells by inhibition of RIP-1 and ERK1/2. Int J Mol Sci 13: 7212-7225, 2012.

30. Azijli K, Yuvaraj S, Peppelenbosch MP, Würdinger T, Dekker H, Joore J, van Dijk E, Quax WJ, Peters GJ, de Jong S and Kruyt FA: Kinome profiling of non-canonical TRAIL signaling reveals RIP1-Src-STAT3-dependent invasion in resistant non-small cell lung cancer cells. J Cell Sci 125: 4651-4661, 2012.

31. Jüttner S, Wissmann C, Jöns T, Vieth M, Hertel J, Gretschel S, Schlag PM, Kemmner W and Höcker M: Vascular endothelial growth factor-D and its receptor VEGFR-3: Two novel independent prognostic markers in gastric adenocarcinoma. J Clin Oncol 24: 228-240, 2006
32. Arinaga M, Noguchi T, Takeno S, Chujo M, Miura T and Uchida Y: Clinical significance of vascular endothelial growth factor $\mathrm{C}$ and vascular endothelial growth factor receptor 3 in patients with nonsmall cell lung carcinoma. Cancer 97: 457-464, 2003.

33. Achen MG, McColl BK and Stacker SA: Focus on lymphangiogenesis in tumor metastasis. Cancer Cell 7: 121-127, 2005.

34. Timoshenko AV, Rastogi S and Lala PK: Migration-promoting role of VEGF-C and VEGF-C binding receptors in human breast cancer cells. Br J Cancer 97: 1090-1098, 2007.

35. Masood R, Kundra A, Zhu S, Xia G, Scalia P, Smith DL and Gill PS: Malignant mesothelioma growth inhibition by agents that target the VEGF and VEGF-C autocrine loops. Int $\mathrm{J}$ Cancer 104: 603-610, 2003.

36. Shimada H, Endo I, Togo S, Nakano A, Izumi $\mathrm{T}$ and Nakagawara G: The role of lymph node dissection in the treatment of gallbladder carcinoma. Cancer 79: 892-899, 1997.

37. Chen Y, Jiang L, She F, Tang N, Wang X, Li X, Han S and Zhu J: Vascular endothelial growth factor-C promotes the growth and invasion of gallbladder cancer via an autocrine mechanism. Mol Cell Biochem 345: 77-89, 2010.

38. Ernst P and Smale ST: Combinatorial regulation of transcription. I: General aspects of transcriptional control. Immunity 2: 311-319, 1995.

39. Fidler IJ: Critical factors in the biology of human cancer metastasis: Twenty-eighth G.H.A. Clowes memorial award lecture. Cancer Res 50: 6130-6138, 1990.

This work is licensed under a Creative Commons Attribution-NonCommercial-NoDerivatives 4.0 International (CC BY-NC-ND 4.0) License. 